University of Nebraska - Lincoln

DigitalCommons@University of Nebraska - Lincoln

Jay F. Storz Publications

Papers in the Biological Sciences

$11-2010$

\title{
Structure and Reactivity of Hexacoordinate Hemoglobins
}

\author{
Smita Kakar \\ lowa State University \\ Federico G. Hoffmann \\ University of Nebraska - Lincoln, fhoffmann2@unl.edu \\ Jay F. Storz \\ University of Nebraska - Lincoln, jstorz2@unl.edu \\ Marian Fabian \\ Rice University \\ Mark S. Hargrove \\ lowa State University, msh@iastate.edu
}

Follow this and additional works at: https://digitalcommons.unl.edu/bioscistorz

Part of the Genetics and Genomics Commons

Kakar, Smita; Hoffmann, Federico G.; Storz, Jay F.; Fabian, Marian; and Hargrove, Mark S., "Structure and Reactivity of Hexacoordinate Hemoglobins" (2010). Jay F. Storz Publications. 46.

https://digitalcommons.unl.edu/bioscistorz/46

This Article is brought to you for free and open access by the Papers in the Biological Sciences at DigitalCommons@University of Nebraska - Lincoln. It has been accepted for inclusion in Jay F. Storz Publications by an authorized administrator of DigitalCommons@University of Nebraska - Lincoln. 


\title{
Structure and Reactivity of Hexacoordinate Hemoglobins
}

\author{
Smita Kakar, ${ }^{1}$ Federico G. Hoffman, ${ }^{2}$ Jay F. Storz, ${ }^{2}$ Marian Fabian, ${ }^{3}$ and Mark S. Hargrove ${ }^{1}$ \\ 1. Department of Biochemistry, Biophysics, and Molecular Biology, Iowa State University, Ames, IA 50011 \\ 2. Department of Biological Sciences, University of Nebraska-Lincoln, Lincoln, NE 68588 \\ 3. Department of Biochemistry and Cell Biology, Rice University, Houston, TX 77251 \\ Corresponding author - M. S. Hargrove, tel 515 294-2616, fax 515 294-0520, email msh@iastate.edu
}

\begin{abstract}
The heme prosthetic group in hemoglobins is most often attached to the globin through coordination of either one or two histidine side chains. Those proteins with one histidine coordinating the heme iron are called "pentacoordinate" hemoglobins, a group represented by red blood cell hemoglobin and most other oxygen transporters. Those with two histidines are called "hexacoordinate hemoglobins", which have broad representation among eukaryotes. Coordination of the second histidine in hexacoordinate $\mathrm{Hbs}$ is reversible, allowing for binding of exogenous ligands like oxygen, carbon monoxide, and nitric oxide. Research over the past several years has produced a fairly detailed picture of the structure and biochemistry of hexacoordinate hemoglobins from several species including neuroglobin and cytoglobin in animals, and the nonsymbiotic hemoglobins in plants. However, a clear understanding of the physiological functions of these proteins remains an elusive goal.
\end{abstract}

Keywords: hexacoordinate hemoglobin, structure, kinetics, ligand binding, evolution, plant hemoglobin, neuroglobin

Abbreviations: $\mathrm{Hb}$, hemoglobin; Hxhb, hexacoordinate hemoglobins; nsHb, nonsymbiotic hemoglobins; Lbs, leghemoglobins; SynHb, Synechocystis sp hemoglobin; Ngb, neuroglobin; Cgb, cytoglobin; GlbX, globin X; Mb, myoglobin; DrosHb, drosophila hb; Mollusk nhb, mollusk nerve hemoglobin; $\mathrm{CO}$, carbon monoxide; NO, nitric oxide; EPR, electron paramagnetic resonance; NMR, nuclear magnetic resonance

\section{Contents}

1. In what organisms are hexacoordinate hemoglobins found? ........................................................................

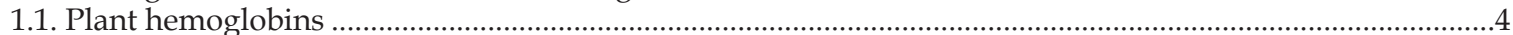

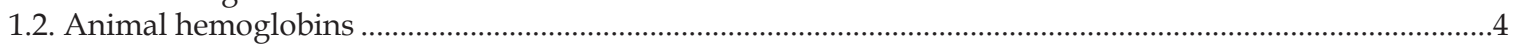

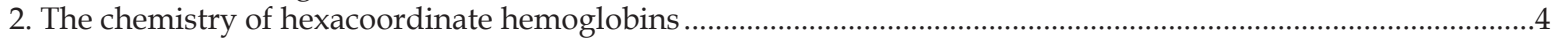

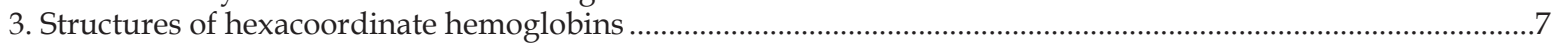

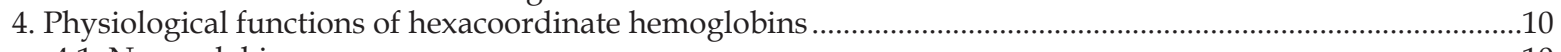

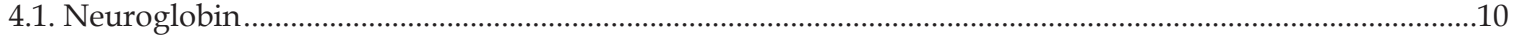

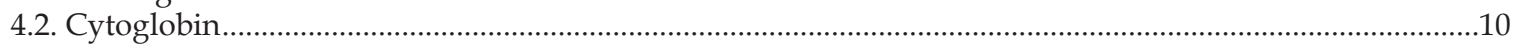

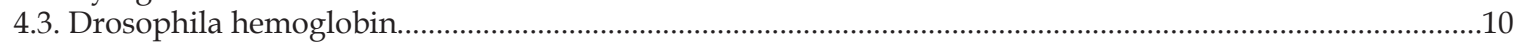

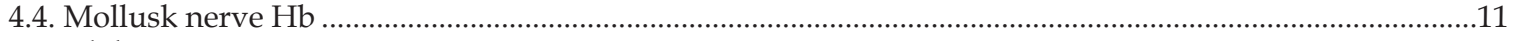

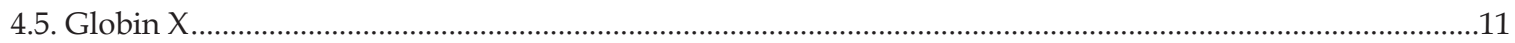

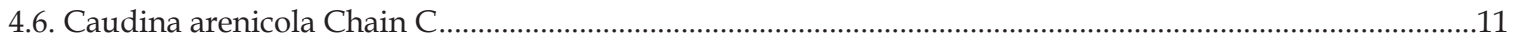

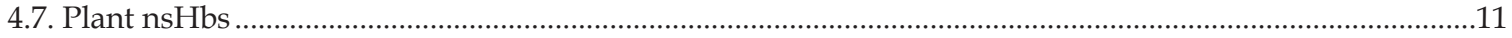

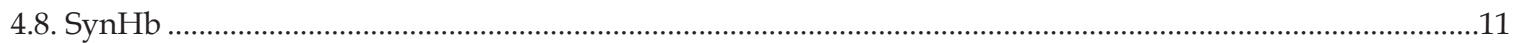

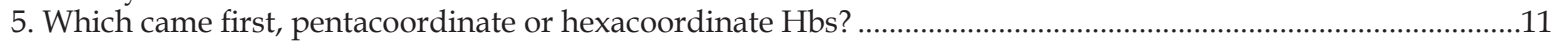

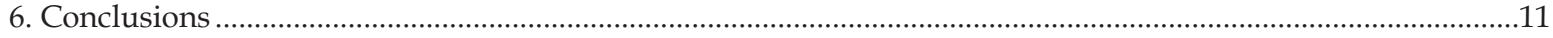

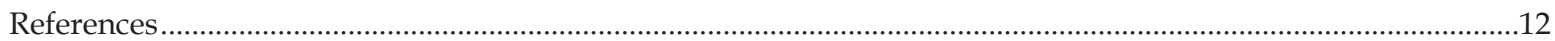

The term "hemoglobin" has spent decades at the forefront of biochemical research, including the eras of "grind-and-find", protein structure determination, and the relationship between protein structure and function. It has also served as a famil- iar target in genomic annotation, and as a guidepost to study the evolution of primary structure and protein function. We have learned over the past fifteen years that most organisms contain genes with homology to globins, and that not all glo- 
bins are oxygen transport proteins [1-4]. In fact, it is presumptuous to assume that all globins use a heme prosthetic group as part of their physiological functions [5]. Most of what has been learned during this period originated from wide spread sequencing of genomes representing all kingdoms of life, followed by biochemical analysis of proteins resulting from select members of these new-found sequences, in most cases using recombinant methods for their production.

The infrastructure for detailed biophysical research with hemoglobins ( $\mathrm{Hbs}$ ) has been in place for decades, established in an effort to understand how the structures of oxygen transport Hbs confer this function. All of the newly discovered Hbs have been naturally welcomed into this framework, which has produced a wealth of structures, spectroscopic characterizations, and biochemical investigations of recombinant $\mathrm{Hbs}$ from the three kingdoms of life. The downside of all the ready physical analysis is that such work, when not guided by knowledge of a clear physiological function, sometimes digresses from biology and can mislead functional hypotheses by asking leading questions. Thus, organizing globins based on function is currently difficult. Nevertheless, irrespective of functional hypotheses, structural and chemical studies of newly discovered $\mathrm{Hbs}$ have revealed unusual behavior that has challenged some of the principles distilled from the wealth of research on oxygen transport Hbs.

The chemistry of heme proteins and hemoglobins is dictated to a large degree by the manner in which the heme group is coordinated to the globin, and the environment of the surrounding heme pocket. The range of coordination states and axial ligands exhibited by heme proteins in general is extensive compared to the subset that have globin folds [6]. The degree of coordination ranges from the NO-bound conformations of soluble guanylate cyclase [7], some H-NOX proteins [8], and cytochrome $c$ [9], which completely lack coordination to the protein, to cytochromes $b 5$, which are bis-histidyl in coordination and unreactive with exogenous ligands. Within the globin class of heme proteins, the unique properties of nitric oxide [10] have been shown to form pentacoordinate NO complexes with myoglobin and blood cell alpha chains $[11,12]$ akin to that of soluble guanylate cyclase, but these conformations are significantly populated only at lower $\mathrm{pH}$ and are probably not common in vivo. There is however at least one hexacoordinate complex of alpha chains that is considered to be of potential physiological importance. Binding of oxy-alpha $\mathrm{Hb}$ to alpha- $\mathrm{Hb}$ stabilizing protein (AHSP) prior to holo-Hb formation leads to the rapid formation of an oxidized (ferric) bis-histidyl complex [13]. The hemichrome structure is thought to be relatively stable, and could provide a mechanism for an inert folding reaction followed by rapid heme iron reduction.

The familiar oxygen transport $\mathrm{Hbs}$ of plants and animals use pentacoordinate heme iron (Figure 1A) to reversibly bind oxygen in the $\mathrm{Fe}^{2+}$ (ferrous) oxidation state. In all cases, a single histidine side chain coordinates an axial site on the heme iron to help hold the prosthetic group in place, leaving the other axial site open for oxygen binding. Only the ferrous oxidation state will reversibly bind oxygen, and the tissues in which these proteins function have mechanisms to prevent or reverse the spontaneous oxidation to the $\mathrm{Fe}^{3+}$ (ferric) oxidation state. In newly discovered $\mathrm{Hbs}$, absent the knowledge of physiological function, there is no way to know what oxidation state is biologically relevant or how heme coordination relates to function. The heme iron could potentially exist (or cycle through) in the $\mathrm{Fe}^{2+}$ (ferrous), $\mathrm{Fe}^{3+}$ (ferric), or $\mathrm{Fe}^{4+}$ (ferryl) oxidation state, attachment to the protein could potentially result from a number of amino acids capable of donating a pair of electrons to form a coordination bond [6], and attachment to the protein could result from one or two coordinate bonds (two if both axial binding sites are filled by proteinaceous amino acids).

In practice, recombinant $\mathrm{Hbs}$ in the laboratory will readily adopt the ferrous and ferric oxidations states, and can be pushed into the ferryl state by exposure to hydrogen peroxide [14-16]. But without knowledge of function in vivo, it is difficult to judge the objective importance of these observations. However, the number of bonds coordinating the heme group can be objectively measured spectroscopically and by observation of protein structure, and has provided an important distinguishing classification for $\mathrm{Hbs}$. In fact, the first discoveries of non-oxygen transport $\mathrm{Hbs}$ in plants and animals revealed recombinant proteins with coordination states distinct from pentacoordinate oxygen transporters [17, 18] (Figure 1B). These Hbs share the features of having their heme groups coordinated by two histidine side chains, one of which is capable of reversible dissociation to allow the stable binding of exogenous ligands like oxygen, carbon monoxide, and nitric oxide. While these proteins do not necessarily share sequence homology, and sequence alone has not yet been used to predict coordination state, the shared structural similarity of six coordinate bonds to the heme iron has resulted in these proteins being collectively referred to as "hexacoordinate" Hbs (hxHbs). The purpose of this review is to describe hexacoordinate $\mathrm{Hbs}$ by comparing their structures, ligand reactivities and biochemical activities.
A

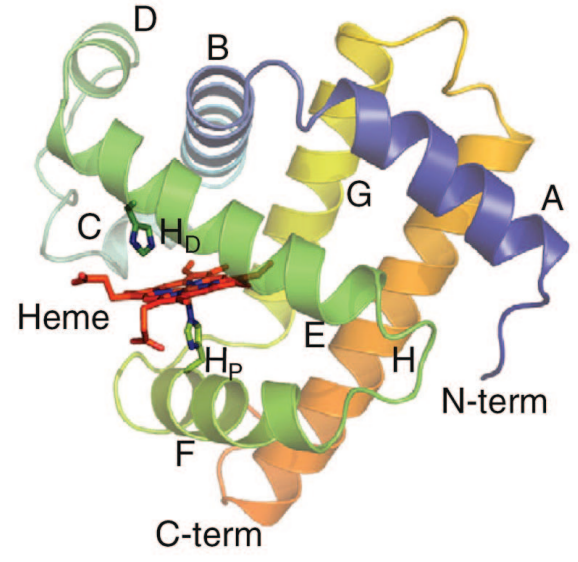

B

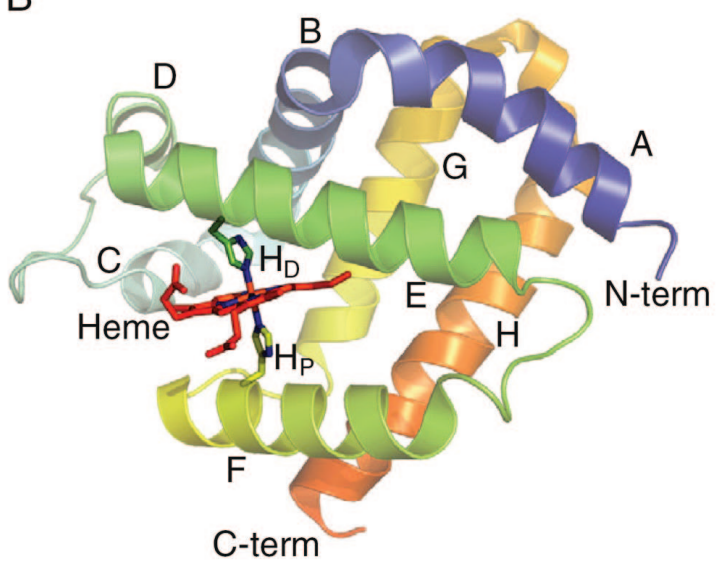

\section{Pentacoordinate $\mathrm{Hb}$}

\section{Hexacoordinate $\mathrm{Hb}$}

Figure 1. Pentacoordinate and hexacoordinate hemoglobins. A) The structure of ferric sperm whale myoglobin (2MBW.pdb) shows a pentacoordinate, low spin heme with an open distal binding site. B) The structure of Neuroglobin (1QIF.pdb) demonstrates hexacoordinate hemoglobin with the binding site occupied by the side chain of the distal histidine. In each structure, eight alpha-helices are labeled (A through $\mathrm{H})$ along with showing the $\mathrm{N}$-terminus $\left(\mathrm{N}\right.$-term), the $\mathrm{C}$-terminus $\left(\mathrm{C}\right.$-term) and the distal $\left(\mathrm{H}_{\mathrm{D}}\right)$ and proximal $\left(\mathrm{H}_{\mathrm{P}}\right)$ histidines. 


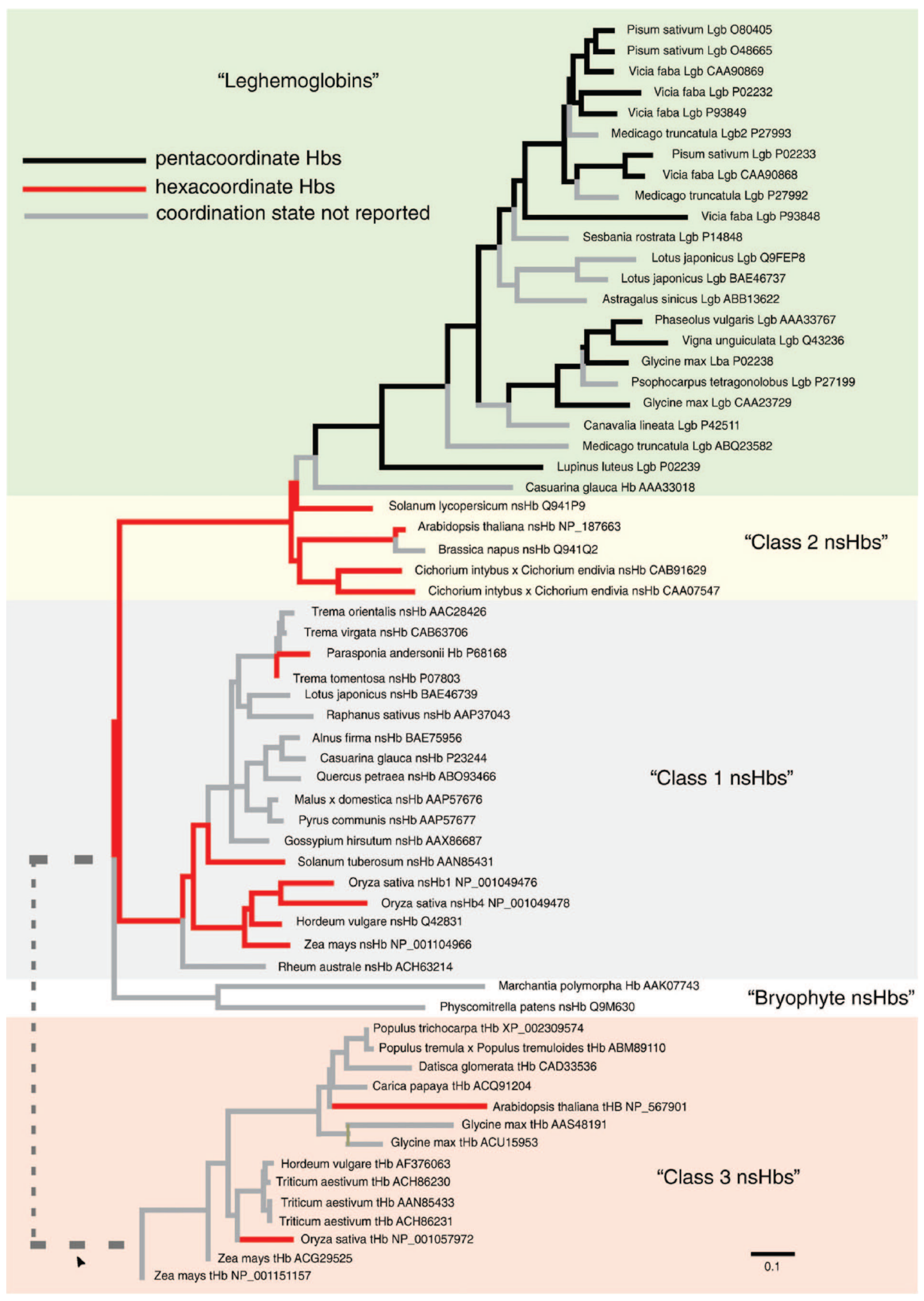

Figure 2. Maximum likelihood phylogram of select plant globin sequences. Plant globins can be classified into three "classes", each containing hexacoordinate members (red lines). The term "nonsymbiotic hemoglobin" (nsHb) is in deference to the previously discovered symbiotic "leghemoglobins", which are pentacoordinate oxygen transporters. 


\section{In what organisms are hexacoordinate hemoglobins found?}

\subsection{Plant hemoglobins}

$\mathrm{HxHb}$ have been found in plants, animals, and cyanobacteria [18-20]. They were first noted in the plant "nonsymbiotic" hemoglobins (nsHbs), which were discovered during a search for globins in plants that are unrelated to oxygen transport [18]. Prior to the discovery of nsHbs, it was thought that Hbs in plants were limited to nitrogen fixing legumes, where these "leghemoglobins" (Lbs) scavenge oxygen and deliver it to respiring symbiotic bacteria in the root nodules [21, 22]. The identification of globin genes in many other plants helped to explain the evolutionary origin of the Lbs, and brought about the continuing question of the physiological function of nsHbs [23]. Since the discovery and characterization of nsHbs in barley [18] and rice [24] nearly 15 years ago, dozens of plant globin genes have been sequenced and can be grouped into three different clades, corresponding to groups of plant $\mathrm{Hbs}$ derived from a common ancestor (Figure 2), that exhibit distinct physical behavior [4].

With the exception of the Lbs, all plant Hbs show some degree of hexacoordinate character. The Class $2 \mathrm{nsHbs}$ have the highest affinities for distal histidine coordination in the ferrous oxidation state $\left(\mathrm{K}_{\mathrm{H}}\right.$ in Table 1$)$, whereas the degree of coordination in Class 1 nsHbs is much less [4, 25]. The Class 3 nsHbs share greater sequence similarity $(40-45 \%)$ with bacterial $\mathrm{Hbs}$ of the "2-on-2" structural motif [26-32] than with the other nsHbs (<25\%) [33], and likely result from horizontal gene transfer from bacteria [34]. Many of the bacterial Hbs are also shorter in primary structure in which the antiparallel helix pairs B/E and G/H are arranged in a "2-on-2" sandwich, but the Class $3 \mathrm{nsHbs}$ are actually longer than the other $\mathrm{nsHb}$ and typical globins. The only reported bacterial $\mathrm{hxHb}$ is found in the cyanobacterium Synechocystis $(S y n \mathrm{Hb})[20,35,36]$, which contains a "2-on-2" $\mathrm{Hb}$ that is hexacoordinate in both the ferrous and ferric oxidation states [37, 38].

\subsection{Animal hemoglobins}

Concurrent with the discovery of hxHbs in plants was the identification of new globin sequences in the genomes of hundreds of species spanning all kingdoms of life [2, 19, 39-44]. Examination of recombinant proteins resulting from many of these gene sequences has identified the presence of hxHbs within each of the three major groups of animal Hbs (Figure 3). Animal Hbs can be grouped into three separate clades in a manner that is consistent with the nature of the circulatory system of the corresponding organism and with how the oxygen transport Hbs

Table 1. Rates and equilibrium constants for hexacoordination by the distal histidine. Kinetic and equilibrium constants for reversible distal histidine coordination.

\begin{tabular}{llllll}
\hline Protein & $\begin{array}{l}E_{\text {mid }} \\
(\mathrm{mv})\end{array}$ & $\begin{array}{l}k_{\mathrm{H} 2} \\
\left(\mathrm{~s}^{-1}\right)\end{array}$ & $\begin{array}{l}k_{-\mathrm{H} 2} \\
\left(\mathrm{~s}^{-1}\right)\end{array}$ & $K_{\mathrm{H} 2}$ & Reference \\
\hline $\mathrm{Mb}$ & 50 & $\sim 0$ & & $\sim 0$ & {$[53]$} \\
$\mathrm{Mb} \mathrm{H64V/V68H}$ & -128 & $>20,000$ & $>200$ & $\sim 100$ & {$[53]^{\mathrm{a}}$} \\
$\mathrm{Ngb}_{\text {human }}$ & -115 & 1900 & 1.5 & 2000 & \\
Ngb $_{\text {mouse }}$ & -129 & 1000 & 0.5 & 2000 & \\
Ngb & & 2500 & 2 & 1250 & {$[39,46,48]^{\mathrm{b}}$} \\
Cgb & -28 & 315 & 1.3 & $\sim 400$ & {$[40,47]$} \\
DrosHb & & 550 & 30 & 18 & {$[49]$} \\
Mollusk nHb & & 14,000 & 1000 & 14 & {$[41]$} \\
Plant nsHb1 (average) $)$ & $\mathbf{1 3 0}$ & $\mathbf{7 5}$ & $\mathbf{1 . 7}$ & \\
Rice nsHb1 & -143 & 75 & 40 & 1.9 & \\
Plant nsHb2 (average) & & $\mathbf{1 5 0 0}$ & $\mathbf{2 5}$ & $\mathbf{8 4}$ & \\
Tomato nsHb2 & & 1400 & 30 & 60 & \\
SynHb & -195 & 4200 & 14 & 300 & {$[48]$} \\
\hline
\end{tabular}

a Average values for members of each class are in bold. The value of $\mathrm{K}_{\mathrm{H} 2}$ for $\mathrm{Mb}{ }_{\mathrm{H} 64 \mathrm{~V} / \mathrm{V} 68 \mathrm{H}}$ is unpublished, and is from a personal communication from John S. Olson; other values are from [53].

${ }^{b}$ For $\mathrm{Ngb}, K_{\mathrm{H}}$ is average of values from these references. are packaged within the circulatory system. In the phylogeny shown in Figure 3, for example, the top-most clade corresponds to arthropod and mollusk $\mathrm{Hbs}$, two groups that have open circulatory systems. The middle clade consists of intracellular oxygen transport $\mathrm{Hbs}$ from organisms that have closed circulatory systems. The bottom-most clade consists of extracellular $\mathrm{Hbs}$ from organisms that have closed circulatory systems.

The animal hxHbs that are most closely related to the cellbound $\mathrm{Hbs}$ in closed circulatory systems are the "cytoglobins"

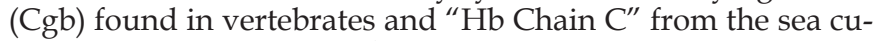
cumber Caudina arenicola $[2,40,45]$. The two other vertebrate hxHbs, "neuroglobins" (Ngb) and "globin X" (GlbX), are more closely related to extracellular oxygen transport Hbs present in animals with closed circulatory systems [19, 43, 44]. In general, the Ngbs are very strongly coordinated by the distal histidine in both the ferrous and ferric oxidation states, Cgbs are intermediate in this regard, and hxHbs from branch 1 of the tree are most weakly hexacoordinate, on par with the nsHbs from plants [40, 41, 46-49] (Table 1).

\section{The chemistry of hexacoordinate hemoglobins}

Because our knowledge of hxHbs is based mainly on in vitro reactions with recombinant proteins, our knowledge of their chemistry and reactions with ligands is limited to what they can do under controlled experimental conditions. And because the experimental questions asked are often influenced by our knowledge of the function and reactivity of oxygen transporters, much of what we know about hxHbs is derived from similar experiments. Thus, the data presented in Tables 1 and 2 and the following discussion of the chemistry and reactivity of $\mathrm{hxHb}$ is grounded in a comparison to their pentacoordinate oxygen transport counterparts.

Absent any bound ligands, myoglobin $(\mathrm{Mb})$ is pentacoordinate in both the ferrous and ferric oxidation states. This is readily evident from electronic absorbance spectra of both oxidation states, and from electron paramagnetic resonance spectroscopy for the ferric protein (Figure 4). The characteristic visible-region absorption bands are weak and broad, with peaks near 500 and $635 \mathrm{~nm}$ for the ferric proteins, and a single asymmetric absorbance band near $555 \mathrm{~nm}$ for the ferrous proteins, indicating that the heme iron is in the high-spin electronic configuration in both oxidation states (Figure 4A) [50]. On the contrary, histidine coordination to the sixth axial position converts the heme iron of $h \times H b s$ to the low spin electronic configuration in both oxidation states giving rise to stronger visible absorbance in the ferric state, and splitting of the ferrous visible absorbance band into two peaks near 560 and $530 \mathrm{~nm}$ (Figure 4B). EPR is a particularly sensitive measure of the spin state in ferric Hbs, where high spin (usually pentacoordinate) Hbs exhibit a strong axial signal at $g=5.4$ and 2 demonstrating a single species in the sample (Figure $4 \mathrm{C}$ ), and low spin $\mathrm{Hbs}$ (like the hxHbs) exhibit weaker and more complex spectra dominated by a rhombic signal with features at $g$ values of 3, 2.2 and 2 (Figure 4D) [51].

While all ferric $\mathrm{hxHb}$ bind the distal histidine with equilibrium constants $\gg 10$ [52], the strength of coordination in the ferrous state is variable (Figure 4E, Table 2) [48]. Ferrous Ngbs, Cgbs, and $\operatorname{Syn} \mathrm{Hb}$ are very tightly coordinated compared to the plant nsHbs, drosophila $\mathrm{Hb}$ (Dros $\mathrm{Hb}$ ), and mollusk nerve $\mathrm{Hb}$ (Mollusk $\mathrm{nHb}$ ). The "Class 3 " nsHbs are low spin in the ferric form, and transition to the high-spin, pentacoordinate state upon reduction [33]. The differential strength of coordination is observed in the lower midpoint reduction potentials of hxHbs (Table 2), which are all well below 0 , and typically near $-130 \mathrm{mV}[46,52,53]$.

Reversible binding of ligands to pentacoordinate $\mathrm{Hbs}$ is a bimolecular process often carried out under pseudo first order reaction conditions, with the ligand in excess of the pro- 


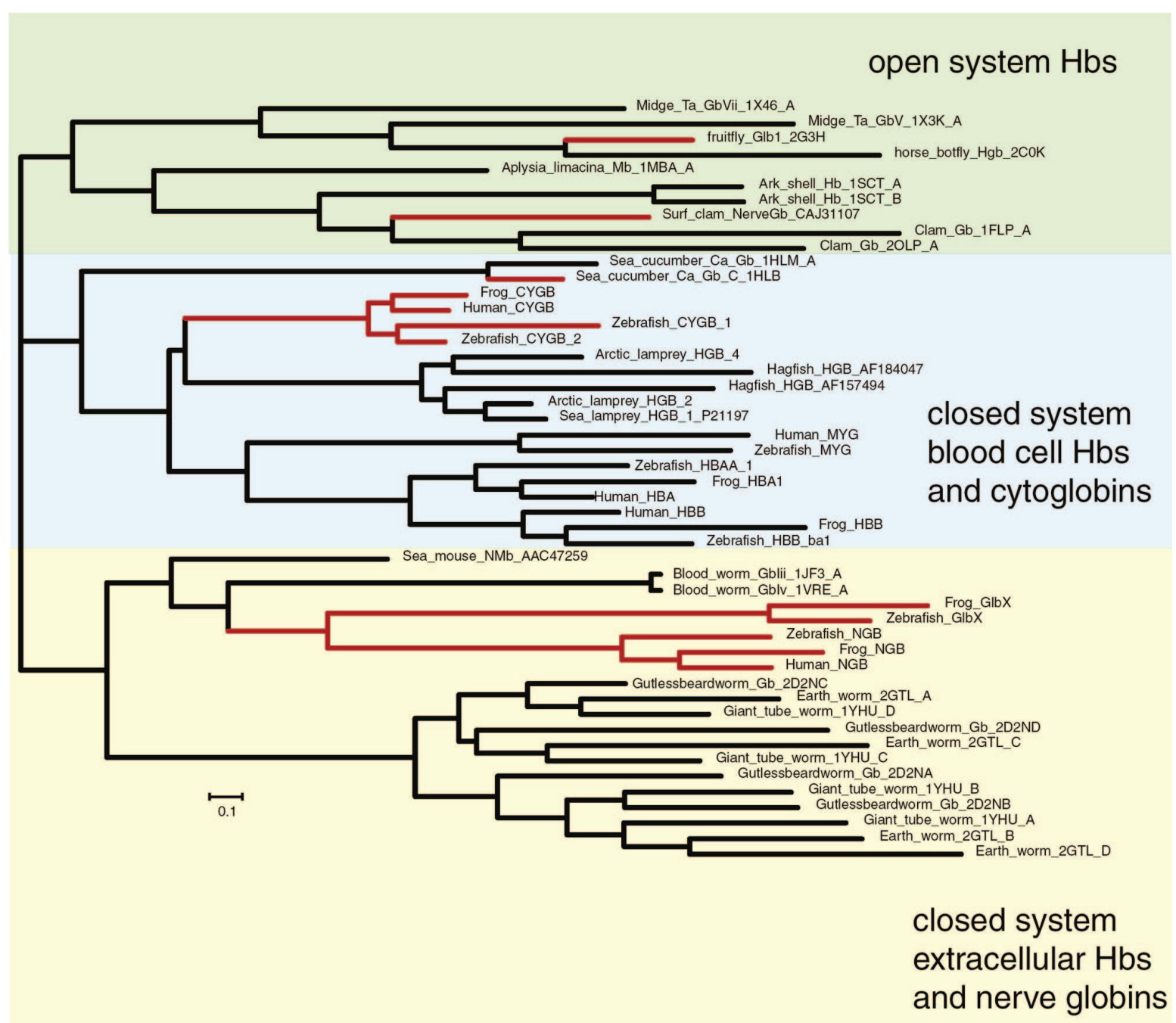

Figure 3. Maximum likelihood phylogram of select metazoan globin sequences. Multicellular animal globin sequences segregate into three major clades, and there are hexacoordinate members of each clade (shown in red). In each case, the phylogeny indicates that hxHbs have evolved from pentacoordinate progenitors.

tein [54]. Under these conditions, the observed rate of binding is linearly dependent on ligand concentration, with the slope of the line equal to the bimolecular rate constant. The first observations of ligand binding to $\mathrm{hxHbs}$ revealed limiting rates of bimolecular binding resulting from coordination of the distal histidine, which blocks the ligand binding site [24, 40, 46, 54]. This complicates ligand binding reactions by preceding bimolecular interactions with a reversible first order event, as shown in Equation (1) [54-56].

$$
H b_{\mathrm{H}} \underset{k_{\mathrm{H}}}{\stackrel{k_{-\mathrm{H}}}{\rightleftarrows}} \mathrm{Hb} b_{\mathrm{P}} \stackrel{k_{L}^{\prime}[L]}{\rightarrow} H b_{L}
$$

The degree to which distal histidine coordination affects binding time courses for exogenous ligands is influenced by two factors [48, 57]: 1) the speed with which the coordinating histidine associates and dissociates from the heme iron, and 2) the equilibrium fraction of protein in the hexacoordinate state. If the speed of coordination $\left(k_{\mathrm{H}}\right)$ and dissociation $\left(k_{-\mathrm{H}}\right)$ is very rapid compared to the association of exogenous ligands $\left(k_{L}^{\prime}[L]\right)$, then the hexacoordination reactions are at fast exchange on the time scale of the ligand binding reaction, and the observed time course will described by a single rate $\left(k_{\mathrm{obs}, \mathrm{L}}\right)$ influenced by the time-average of all three reactions.

$$
K_{\mathrm{obs}, L}=\frac{k_{-\mathrm{H}^{\prime}} k^{\prime}[L]}{k_{\mathrm{H}}+k_{-\mathrm{H}}+k_{L}^{\prime}[L]}
$$

If the speed of coordination is much slower than exogenous ligand binding, the observed time course will be limited by histidine dissociation and will potentially exhibit two phases, one for the fraction of $\mathrm{Hb}$ in the hexacoordinate state, and one for the fraction that is pentacoordinate.

$$
\Delta A_{\text {obs }}=\Delta A_{\mathrm{T}}\left(F_{\mathrm{P}} e^{-k_{L}^{\prime}[L]^{*} t}+F_{\mathrm{H}} e^{-k_{\mathrm{obs}, L}^{\prime}[L]^{*} t}\right)
$$

Regardless of the kinetics of the reaction, the influence of hexacoordination on equilibrium affinity constants is directly related to the affinity constant for histidine coordination $[17,40]$.

$$
K_{\text {effective }}=\begin{gathered}
K_{\text {pentacoordinate }} \\
1+K_{\mathrm{H}}
\end{gathered}
$$

Equation (4) demonstrates how hexacoordination could augment the innate equilibrium affinity constant of a pentacoordinate $\mathrm{Hb}$ by lowering the effective strength of binding [17, $40,46]$.

The reaction central to the function of oxygen transport $\mathrm{Hbs}$ such as $\mathrm{Mb}$ and red blood cell $\mathrm{Hb}$ is the reversible binding of oxygen. The ferrous form of these proteins reacts with oxygen reversibly to form a stable protein usually referred to as the "oxy-ferrous" complex, although the exact electronic state of the oxygen and heme iron are still in question. There is evidence to support the oxygen bound complex existing mainly 
Table 2. Kinetic and equilibrium constants for ligand binding to ferrous hexacoordinate hemoglobins. Kinetic and equilibrium constants for ligand binding to ferrous Hexacoordinate hemoglobins.

\begin{tabular}{|c|c|c|c|c|c|c|c|c|c|}
\hline Proteins & $\begin{array}{l}k^{\prime} \mathrm{CO}_{\text {pent }} \\
\left(\mu \mathrm{M}^{-1} \mathrm{~s}^{-1}\right)\end{array}$ & $\begin{array}{l}k_{\mathrm{CO}} \\
\left(\mathrm{s}^{-1}\right)\end{array}$ & $\begin{array}{l}K_{\mathrm{CO}} \\
\left(\mu \mathrm{M}^{-1}\right)\end{array}$ & $\begin{array}{l}k_{\mathrm{O} 2}^{\prime} \\
\left(\mu \mathrm{M}^{-1} \mathrm{~s}^{-1}\right)\end{array}$ & $\begin{array}{l}k_{\mathrm{O} 2,1} \\
\left(\mathrm{~s}^{-1}\right)\end{array}$ & $\begin{array}{l}\mathrm{K}_{\mathrm{O} 2} \\
\left(\mu \mathrm{M}^{-1}\right)\end{array}$ & $\begin{array}{l}P_{50} \text { (torr) } \\
\text { from kinetics }\end{array}$ & $\begin{array}{l}P_{50} \text { (torr) } \\
\text { from EQ }\end{array}$ & $\begin{array}{l}k_{\text {autpx }} \\
\left(\mathrm{s}^{-1}\right)^{-}\end{array}$ \\
\hline $\mathrm{Mb}$ & 0.51 & 0.02 & 25.5 & 17 & 15 & 1.1 & 0.5 & 0.33 & \\
\hline $\mathrm{Mb} \mathrm{H} 64 \mathrm{~V} / \mathrm{V} 68 \mathrm{H}$ & 0.1 & 0.005 & 15 & & & & & & Fast \\
\hline $\mathrm{Ngb}_{\text {mouse }}$ & 72 & 0.013 & 2.7 & 200 & 0.4 & 0.25 & 2.4 & 2.2 & $19(37)$ \\
\hline $\mathrm{Ngb}_{\text {zebrafish }}$ & 70 & na & na & 250 & 0.3 & 0.7 & 0.9 & 0.7 & \\
\hline $\mathrm{Cgb}$ & 5 & 0.003 & 4 & 30 & 0.35 & & 3 & 1 & \\
\hline nsHb1 (average) & 8.4 & na & na & 67 & 0.14 & 410 & 0.002 & & \\
\hline Rice nsHb1 & 6.8 & 0.001 & 2300 & 60 & 0.038 & 540 & & & $0.08(20, \mathrm{pH} 7)$ \\
\hline nsHb2 average & 39 & 0.001 & 460 & 76 & 1.1 & 2.9 & 0.2 & & \\
\hline Tomato nsHb2 & 26 & na & na & 45 & 0.4 & 1.8 & 0.3 & & \\
\hline Syn $\mathrm{Hb}$ & 90 & na & na & 240 & 0.014 & 57 & 0.01 & & \\
\hline
\end{tabular}

References for these values are as follows: $\mathrm{Mb}[50,154], \mathrm{Mb} \mathrm{H64V/V68H} \mathrm{(average} \mathrm{values} \mathrm{from} \mathrm{human} \mathrm{and} \mathrm{pig} \mathrm{[53]),} \mathrm{Ngb}{ }_{\mathrm{human}}(\mathrm{CO}$ values [17, 39, 46], $\mathrm{O}_{2}$ (average values from [17, 39, 155]), $\mathrm{Ngb}_{\text {mouse }}\left(\mathrm{O}_{2}\right.$ values [155], $\mathrm{CO}$ values [46]), $\mathrm{Ngb}_{\text {zebrafish }}$ [39, 156], $\mathrm{Cgb}$ [40], $\mathrm{O}_{2}$ values [40] and [47], Dro$\mathrm{sHb}$ [49], Mollusk $\mathrm{Hb}$ [41], nsHb1 (average values [24]), nsHb2 [4] (CO off values [157]), SynHb [35].

A

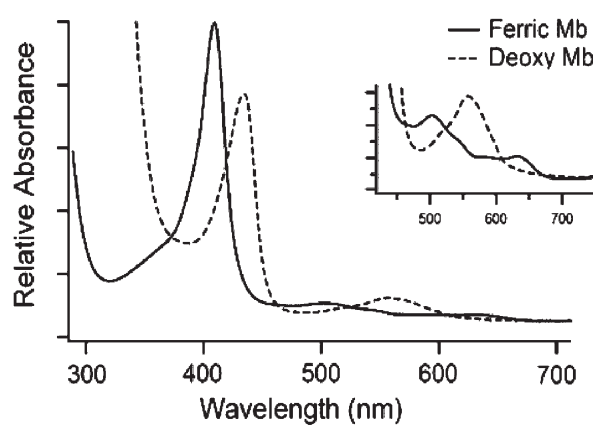

C

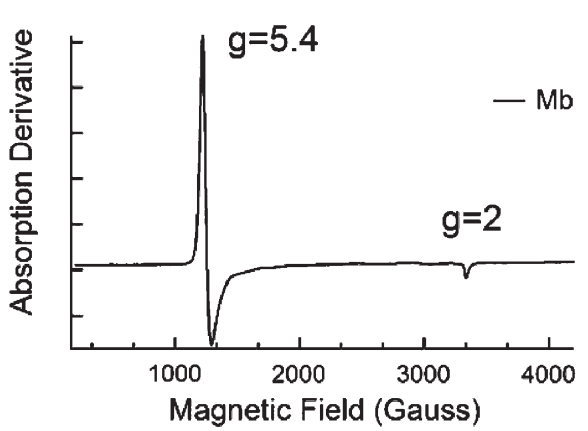

$E$

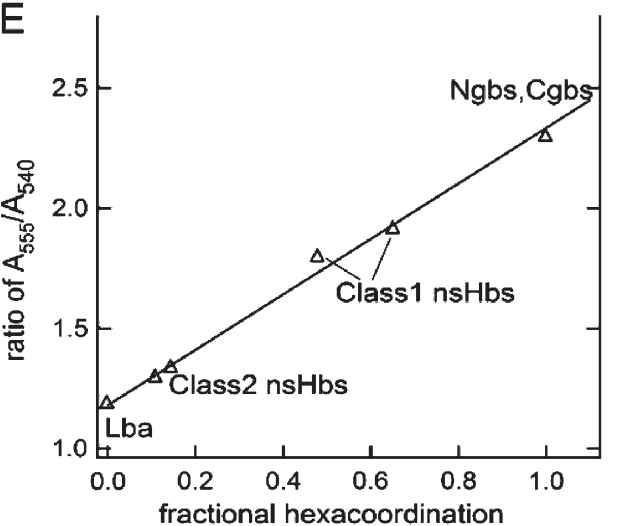

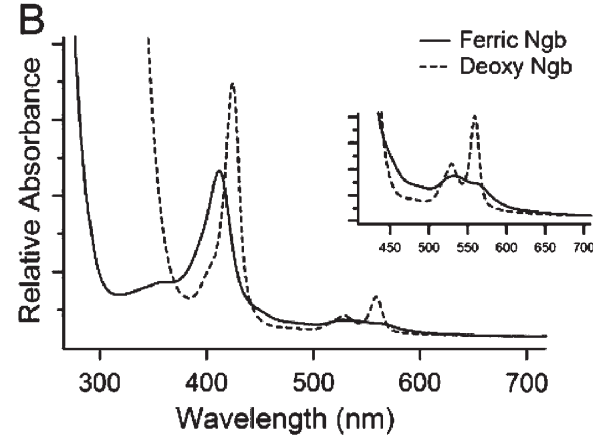

D

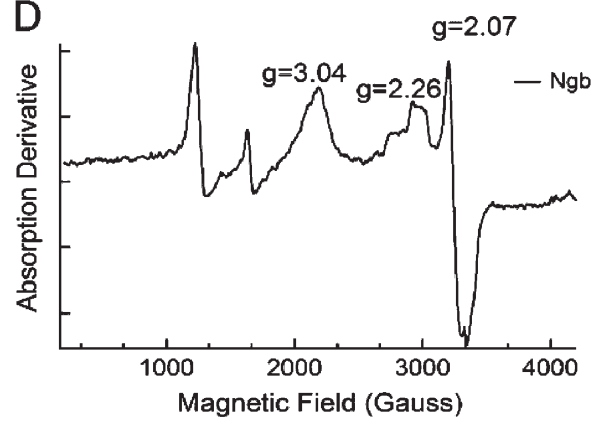

Figure 4. Electronic and paramagnetic spectral characteristics of hxHbs. A) Absorbance spectra of ferric and ferrous sperm whale Mb demonstrate characteristics of high spin, pentacoordinate hemoglobins. B) Absorbance spectra of Ngb in the ferric and ferrous oxidation states demonstrate characteristics typical of low spin hxHbs. C) The EPR spectrum of ferric sperm whale Mb shows the axial high-spin signal of iron at $g=5.4$ and $2 \mathrm{D})$ The EPR spectrum of a low spin heme with $g$ values of 3.04, 2.26 and 2.07, characteristic of a low spin iron as depicted by Ngb. EPR spectra were collected at $10 \mathrm{~K}$ with amplitude modulation of $10 \mathrm{G}$ and frequency of $9.26 \mathrm{GHz}$. 


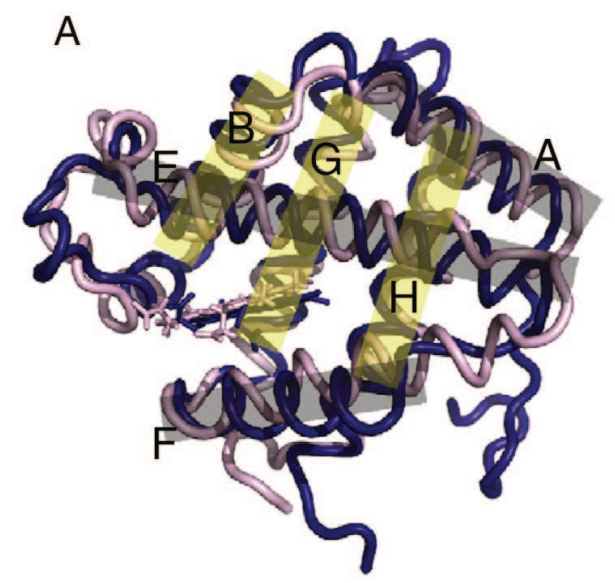

B

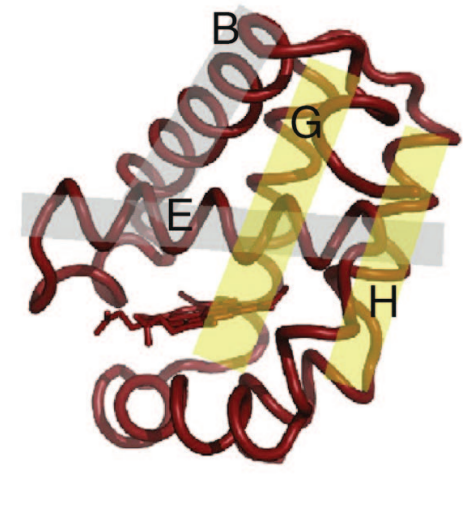

Figure 5. Structural features of hxHbs. A) Rice nsHb1 overlayed with DrosHb shows a "3-on-3" globin core composed the A, E, and F helices stacking on top of the B, G, and H helices. B) The structure of Syn Hb belongs to structural class of globins with a "2-on-2" helical core consisting of the $\mathrm{G}$ and $\mathrm{H}$ helices stacking against the $\mathrm{B}$ and $\mathrm{E}$ helices. The N-terminal end of Helix $\mathrm{A}$ is largely truncated and CD loop and D-helix region shortened to three residues.

Table 3. Rates and equilibrium constants for ligand binding to ferric hexacoordinate hemoglobins, and for the NOD reaction. Kinetic and equilibrium constants for ligand binding to ferric hexacoordinate hemoglobins

\begin{tabular}{|c|c|c|c|c|c|c|}
\hline Protein & $\begin{array}{l}k_{\mathrm{CN}}^{\prime} \\
\left(\mathrm{M}^{-1} \mathrm{~s}^{-1}\right)\end{array}$ & $\begin{array}{l}K D_{\mathrm{CN}} \\
(\mathrm{mM})\end{array}$ & $\begin{array}{l}k_{\text {azide }}^{\prime} \\
\left(\mathrm{M}^{-1} \mathrm{~s}^{-1}\right)\end{array}$ & $\begin{array}{l}K D_{\text {azide }} \\
(\mathrm{mM})\end{array}$ & $\begin{array}{l}k_{N O}^{\prime} \\
\left(\mu M^{-1} s^{-1}\right)\end{array}$ & $\begin{array}{l}\left.k_{\mathrm{NOD}^{\prime}} \mathrm{s}^{-1}\right) \\
\left(\mu \mathrm{M}^{1} \mathrm{~s}^{-1}\right)\end{array}$ \\
\hline $\mathrm{Mb}$ & 320 & 0.001 & 2900 & 0.034 & 22 & $34 \mathrm{~s}^{-1}$ \\
\hline $\mathrm{Ngb}$ & 1.6 & & & & & $300 \mathrm{~s}^{-1}$ \\
\hline $\mathrm{Cgb}$ & & & & & & $500 \mathrm{~s}^{-1}$ \\
\hline DrosHb & 180 & & & & & \\
\hline $\mathrm{nsHb1}$ & 1.8 & & & 0.625 & & $100 \mathrm{~s}^{-1}$ \\
\hline $\operatorname{Syn} \mathrm{Hb}$ & 0.7 & 2 & & 200 & & $\sim 100 \mathrm{~s}^{-1}$ \\
\hline
\end{tabular}

References for these values are as follows: $\mathrm{Mb}$ [55] $\left(k_{\mathrm{NOD}}[68]\right), \mathrm{Ngb}$ $\left(K_{\mathrm{D}, \mathrm{CN}}[15], k_{\mathrm{NOD}}[79]\right), \mathrm{Cgb}[75], \mathrm{nsHb} 1$ [75], SynHb [37] $\left(k_{\mathrm{NOD}}[75]\right.$, estimated from scavenging), DrosHb [49].

as $\mathrm{Fe}^{3+}-\mathrm{O}_{2}{ }^{-}$, but upon reversible dissociation of oxygen, the heme iron is left in the $\mathrm{Fe}^{2+}$ state [50]. Occasionally, $\mathrm{O}^{2-}$ will dissociate leaving the $\mathrm{Fe}^{3+}$ heme iron in one mechanism of oxidation (or "autooxidation") of the $\mathrm{Hb}$ [58]. This process is relatively slow in oxygen transport Hbs due to stabilization of bound oxygen by the distal histidine [59], but there are many features of $\mathrm{Hb}$ structure that can affect rates of autooxidation by allowing solvent access to the heme pocket, and in ways that are not completely understood [60, 61]. The mechanisms used to establish appropriate oxygen binding kinetics (and thus affinities) in oxygen transport proteins involve the combined efforts of the proximal and distal histidines [22, 59]. In general, to facilitate oxygen diffusion, the oxygen dissociation rate constant must be at least $1 \mathrm{~s}^{-1}$, affinities must be appropriate to maintain fractional saturation between the source and sink, and the $\mathrm{Hb}$ concentration must be higher than that of oxygen in solution [4, 62-64].

Due to the augmentation of affinity by hexacoordination (Equation (4)), several hxHbs have affinity constants appropriate for oxygen transport $[4,17,40]$. However, rates of oxygen dissociation from $\mathrm{hxHbs}$ are generally too slow for oxygen transport, with the exception of the mollusk $\mathrm{nHb}$, DrosHb, and the Class 2 nsHbs [4, 24, 41, 42, 48]. Of the hxHbs for which autooxidation has been measured, rates are generally much faster than the pentacoordinate Hbs [46]. The reasons for the rapid rates of oxidation are not well understood, but could be related to rates of electron transfer, which is generally faster in hxHbs [65]. The rate constants for association and dissociation of oxygen and other diatomic ligands (like $\mathrm{CO}$ ) are not exceptional in hxHbs, and fall within the range observed for the variety of pentacoordinate $\mathrm{Hbs}$ that have been reported [63]. Due to the increased strength of coordination by the dis- tal histidine in the ferric oxidation state, ferric hxHbs are generally less reactive than their ferrous counterparts. This is indicated by generally slow and weak binding to ferric ligands such as cyanide and azide (Table 3 ).

Reaction of $\mathrm{Hbs}$ with NO and other nitrogenous compounds of various oxidation states have been reported since the discovery of the role of $\mathrm{NO}$ as a biological signaling molecule that acts through binding the heme group of guanylyl cyclase [66] and [67]. It has been demonstrated that blood cell $\mathrm{Hb}$ and $\mathrm{Mb}$ are likely scavengers of $\mathrm{NO}$ in vivo [68-70], and that bacterial and fungal "flavohemoglobins" (flavoHbs) are scavengers of NO in those organisms [71]. While there is still some discussion of the mechanisms of these reactions [72], the most likely is the reaction of $\mathrm{NO}$ with oxy-ferrous $\mathrm{Hb}$, yielding nitrate and ferric $\mathrm{Hb}$ (known as the nitric oxide dioxygenase reaction, or NOD) [68, $70,71,73]$. The possibility of a similar function has been tested in several hxHbs. In all cases, ferrous hxHbs will bind reversibly to NO [15], the ferric forms will react with NO [74] in some cases showing slow reduction [15, 75-78], and the oxy-ferrous hxHbs will scavenge NO resulting in their oxidation (Table 3 ) $[75,79-83]$. In spite of the fact that the efficiency of these reactions is at best on-par with $\mathrm{Mb}$ and red blood cell $\mathrm{Hb}$, and is certainly limited in vivo by as-of-yet unknown mechanisms for rereduction of the heme iron [4], observation of the NOD reaction has been proposed as support for an NO scavenging function in nsHbs [80, 84], Ngbs [79], and Cgbs [85]. However, unlike $\mathrm{Mb}$ and red blood cell $\mathrm{Hb}$, whose high concentrations allow them to serve as effective NO scavengers in vivo in spite of relatively slow reduction mechanisms, hxHbs are present in very low concentrations, and only one specific reductase (for a nsHb [86]) has been identified that might support catalytic NO scavenging. Thus, there is still little direct chemical evidence supporting hx$\mathrm{Hbs}$ functioning as NO scavengers to a degree greater than $\mathrm{Mb}$ and red blood cell $\mathrm{Hb}$.

\section{Structures of hexacoordinate hemoglobins}

There are ten crystal structures of unbound and ligand-bound $\mathrm{hxHbs}$ published to date [37, 42, 87-93] (The PDB entries are listed in Figure 6). These include structures of hexacoordinate representatives of each of the three branches of the animal phylogenetic tree, one of the three "classes" of plant hxHbs, and prokaryotic $S y n \mathrm{Hb}$. In addition, the structure of a hexacoordinate globin domain from the multi-domain sensor GLB-6 of C. elegans has been solved [94]. Evaluation of quaternary structure from these crystal structures suggests that mouse $\mathrm{Ngb}$ and DrosHb are monomeric [46, 49], and that rice $\mathrm{nsHb}$ and Cgb are dimeric [95-97]. Direct measurement of quaternary structure in solution by analytical ultracentrifugation 

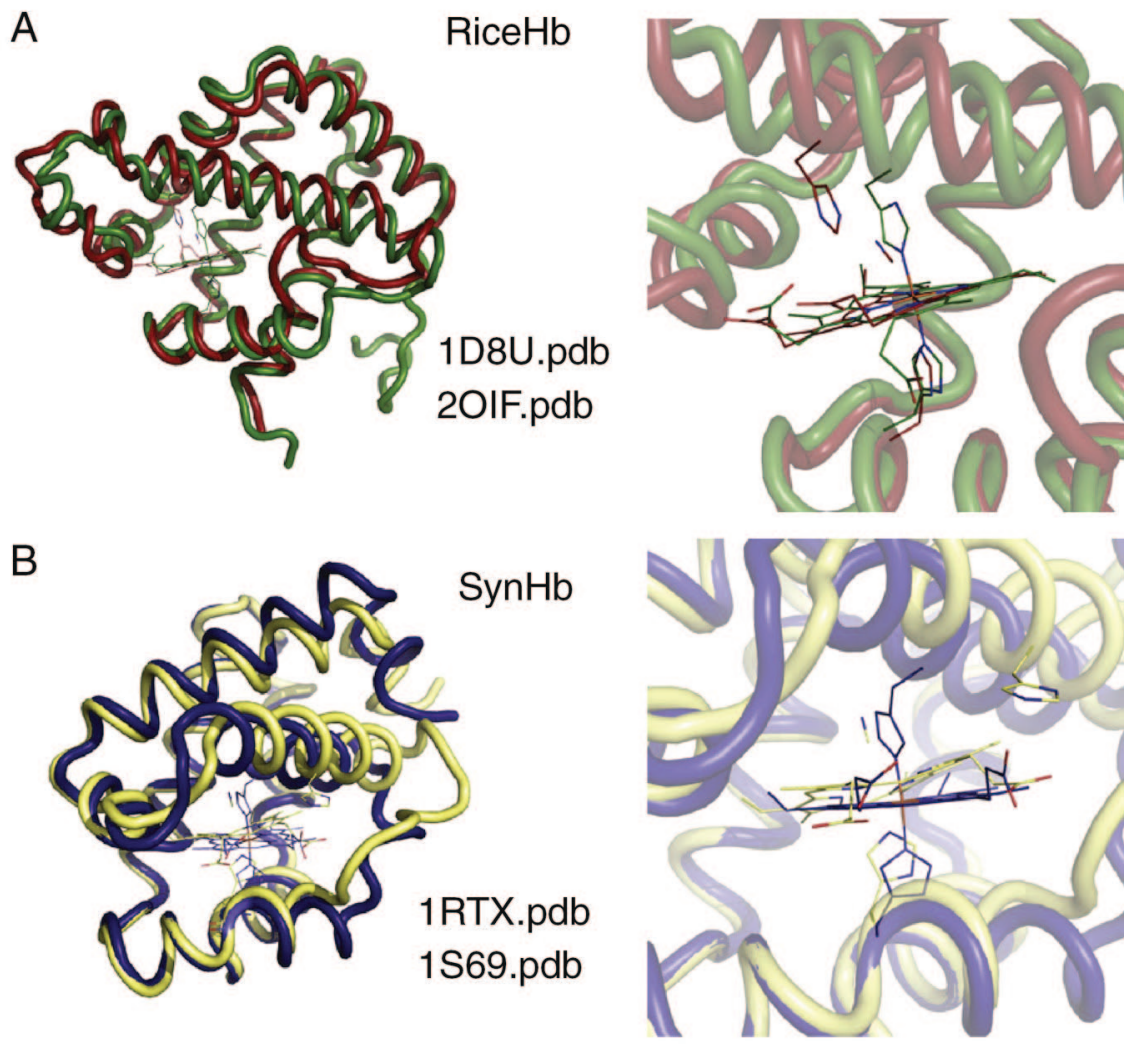

C
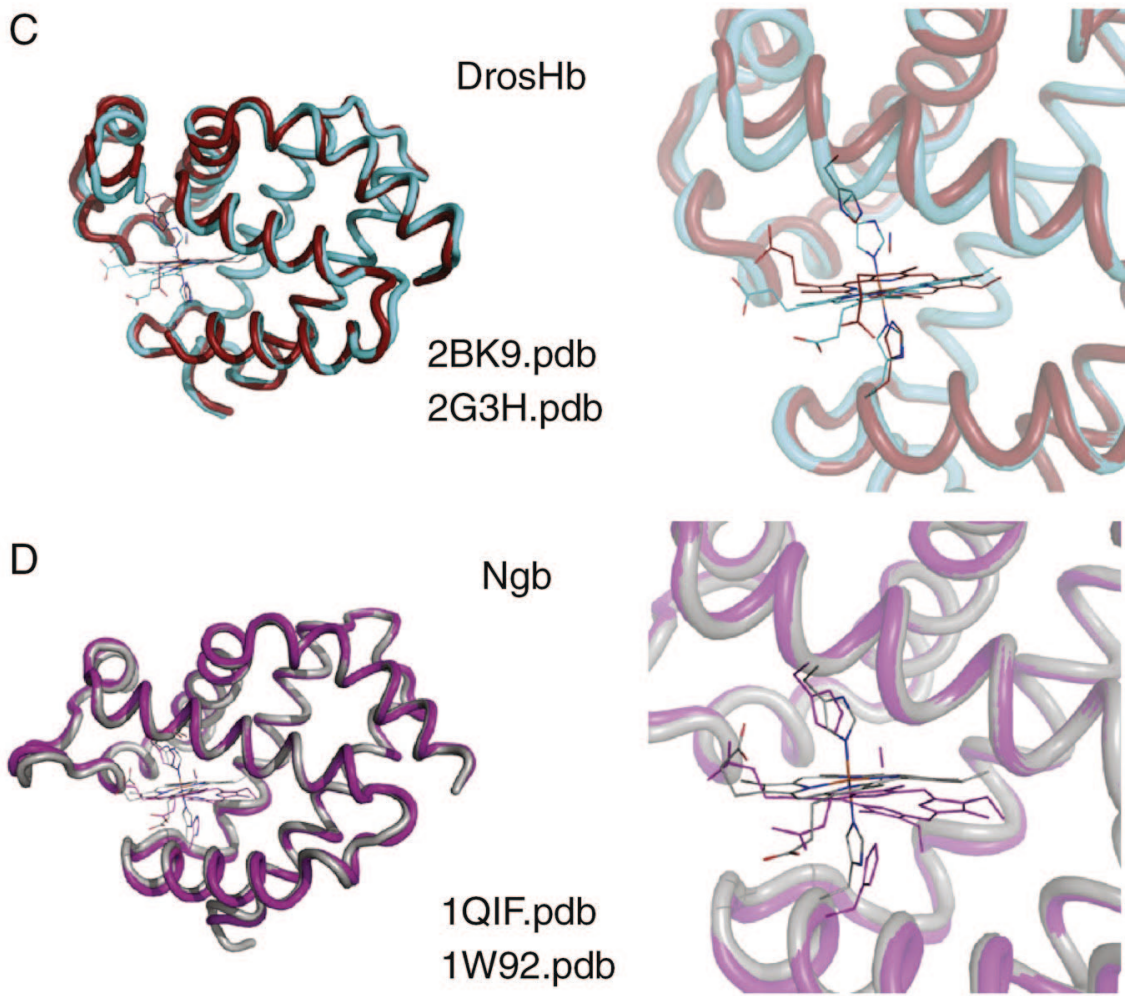

Figure 6. Structural changes upon ligand binding in hxHbs. These are structural overlays of A) Rice hxHb, B) Drosophila hxHb, C) Syn Hb, and $\mathbf{D}$ ) Mouse Ngb in the hexacoordinate and exogenous ligand-bound states. E) Plot of root mean square deviation between hexacoordinate and ligandbound crystal structures for each of the proteins above.

has shown that rice $\mathrm{nsHb}$ dimerizes with a dissociation equilibrium constant of $86 \mu \mathrm{M}[98]$, and that mouse $\mathrm{Ngb}$ is in fact monomeric [46]. Attempts to measure cooperativity in ligand binding studies with $\mathrm{Ngb}$ and $\mathrm{Cgb}$ by Weber and coworkers have shown Hill coefficients of $\sim 1$ for Ngb consistent with it being monomeric, and $0.63-1.63$ for $\mathrm{Cgb}$, implying possible heme-heme interactions for a dimer [99].

In general, the monomeric units of each structure of the eukaryotic hxHbs share the characteristic globin fold of eight helices (labeled A through H, Figure 1) with a "3-on-3" helix as- 


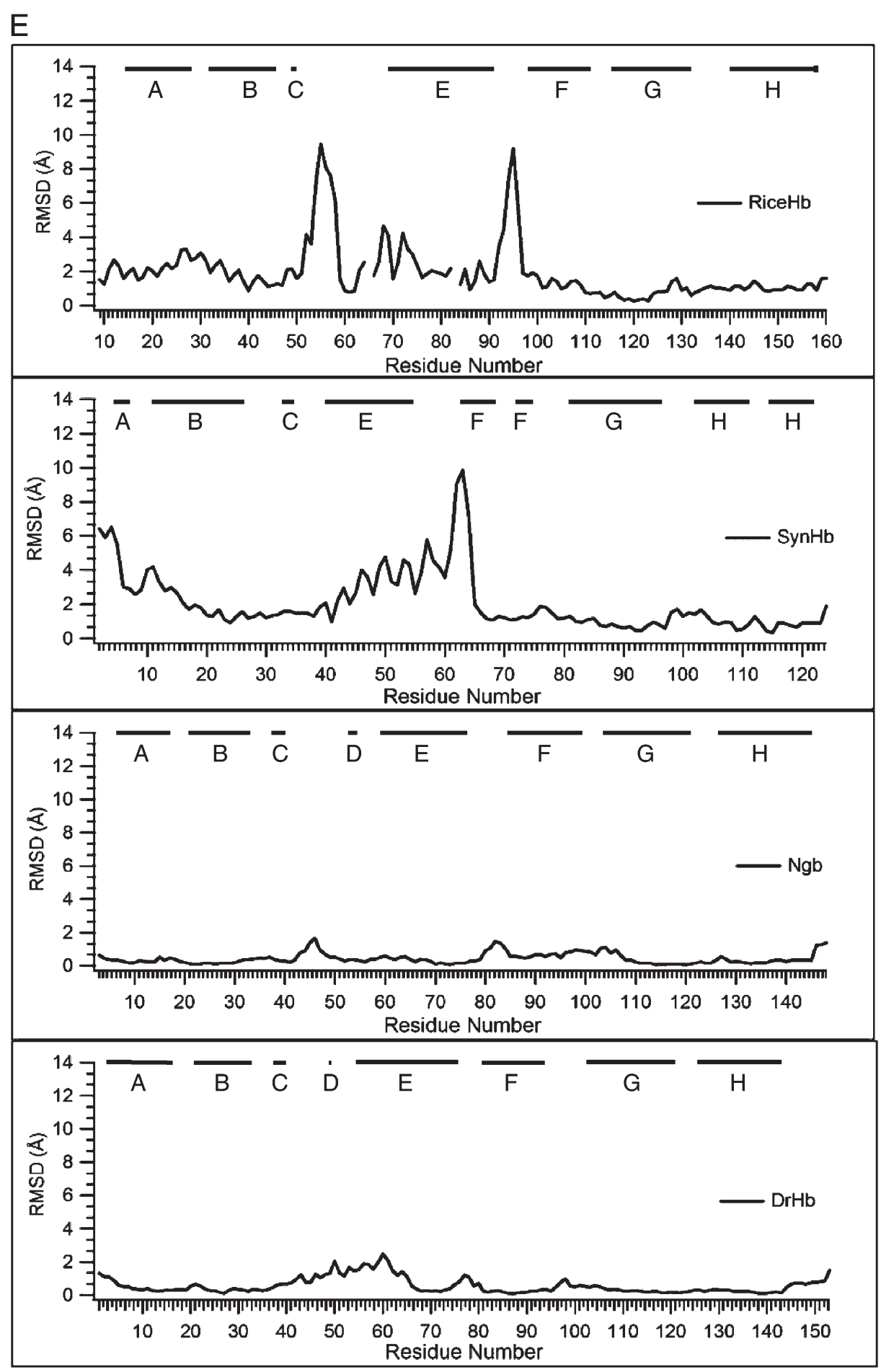

Figure 6. (Continued)

sembly (Figure 5A). The antiparallel sets of helices A/E/F and B/G/H are positioned into a 3-on-3 "sandwich" arrangement. This is in contrast to $\mathrm{SynHb}$, which has the "2-on-2" a-helical "sandwich" fold common to many bacterial Hbs [100] (Figure 5B). Among the eukaryotic hxHbs, the presence of a conspicuous D helix is variable [101], and the folding and stability of this helix has been implicated in the control of reversible distal histidine coordination [91, 102]. Each hxHb crystal structure shows clear coordination by both the distal and proximal histidines. Additionally, there have been NMR, EPR, and vibrational spectroscopic characterizations to test heme iron hexacoordination in solution. Resonance Raman and EPR have confirmed heme iron hexacoordination in the ferric and the ferrous states of mouse Ngb [103], but NMR studies of reveal axial histidine orientations that are not consistent with those seen in crystal structures [14, 88, 104-106]. It is believed that this inconsistency may be due to the higher solvent content in solution, and fewer hydrogen bond acceptors N-H protons of the coordinating histidines [105]. EPR spectroscopic investigations of mouse Ngb by Vinck and coworkers are consistent with the X-ray diffraction data of the ferric protein [107, 108].

One of the most unusual properties of hxHbs is their ability to bind exogenous ligands. Other heme proteins with bis-histidyl coordination do not bind ligands [109, 110], and a hexacoordinate $\mathrm{Mb}$ mutant protein is structurally constrained, and limited in its ability to bind exogenous ligands [53]. Thus, there has 
been interest in observing the structural changes accompanying ligand binding in the context of naturally occurring hxHbs. Structures of hexacoordinate and ligand-bound hxHbs have been solved for $\mathrm{Ngb}[88,89,111]$, class 1 plant nsHbs [91, 92], Dros $\mathrm{Hb}[42,90]$, and $\mathrm{Syn} \mathrm{Hb}[37,93]$. The structural rearrangements revealed for each protein are surprisingly distinct. In the case of class 1 plant nsHbs, distal histidine dissociation from the heme iron is accompanied by rotation and translation of the $\mathrm{E}$ helix, formation of a D helix through contacts that span several helices, and development of several new trans-helical contacts in the EF turn (Figure 6A). Figure 6E shows the RMS deviation between ligand-bound and hexacoordinate $\mathrm{nsHb}$, indicating that most of the changes are associated with the E helix and its termini. The structured D helix and the stabilization of the EF turn are believed to support the pentacoordinate E-helix position. The structure of ligand-bound rice $\mathrm{nsHb}$ is consistent with the structures of Lbs, which evolved from class $2 \mathrm{nsHbs}$ to become fixed in the pentacoordinate configuration [92, 112].

In the case of cyanide-bound $S y n \mathrm{Hb}$, the heme is tilted by $\sim 6$ degrees from the orientation seen in the unliganded structure. The A and B helices swing inward towards the heme, and the A helix lies in close proximity to the E helix (Figure 6B). Additionally, the E helix and EF loop shift outward away from the heme cofactor in ligand-bound $S y n \mathrm{Hb}[37,93]$. In general, ligand binding in plant $\mathrm{nsHbs}$ and bacterial $\mathrm{Hbs}$ involves large-scale motions of the E helix. This is evident from the root mean square deviation between unbound and bound ligand states for Rice $\mathrm{Hb} 1$ and $\mathrm{Syn} \mathrm{Hb}$ (Figure 6E). Structures of Dro$\mathrm{sHb}$ reveal translation and flattening of the heme inside the heme pocket, and heme rotation accompanying ligand binding. A rearrangement of the $\mathrm{CD}$ loop and amino terminal half of the E-helix region is also observed upon ligand binding [42, 90]. However, these conformational changes do not involve large movements of E helix, as seen in nsHbs (Figure 6C).

In contrast to the examples above, the structural transition exhibited by mouse Ngb upon ligand binding is very modest (Figure $6 \mathrm{D}, \mathrm{E}$ ). The heme slides deeper into the heme pocket away from the distal histidine to produce a binding site, but the overall protein structure is not significantly altered [89]. However, the ligand-bound crystal was prepared by reduction and carbon monoxide $(\mathrm{CO})$ exposure to ferric hexacoordinate crystals, and the crystals had to be frozen prior to data collection to avoid cracking [89]. In fact, many hxHb crystal forms shatter when exogenous ligands are introduced, consistent with a structural change incompatible with the crystal lattice. Thus, it is possible that the CO-bound murine $\mathrm{Ngb}$ structure is not at equilibrium and that a larger structural change might be observed in crystals grown in the presence of a bound exogenous ligand.

\section{Physiological functions of hexacoordinate hemoglobins}

\subsection{Neuroglobin}

Because $\mathrm{Ngb}$ is found in the human brain, retina, and other nervous system tissues, the discovery of its physiological function has received a disproportionate amount of attention [113].

1) Based on sequence similarity between Ngb and G-protein regulators, Wakasugi and coworkers have proposed a role for Ngb in G-protein mediated signaling [14, 114, 115]. Antibody pull-down assays and surface plasmon resonance experiments have demonstrated binding of $\mathrm{Ngb}$ to human $\mathrm{Ga}_{\mathrm{i} / \mathrm{o}^{\prime}}$ one of the many Ga proteins associated with heterotrimeric $\mathrm{G}$ protein signaling in animals. Binding occurs only to the GDP-bound (inactive) form of $\mathrm{Ga}_{\mathrm{i} / \mathrm{o}^{\prime}}$, which prevents $\mathrm{Ga}_{\mathrm{i} / \mathrm{o}}$ from being recycled. As $\mathrm{Ga}_{\mathrm{i} / \mathrm{o}}$ inactivation has been linked to protection of neurons during oxidative stress [116], Ngb could serve as a mechanism to limit ischemic damage by mitigating the deleterious effects of $\mathrm{Ga}_{\mathrm{i} /}$ ${ }_{0}$ :GDP [117]. Although there is significant sequence conservation among $\mathrm{Ngb}$ sequences from various species, this activity is not exhibited by other Ngbs, such as that from zebrafish [115]. Thus, these observations tend to question the importance of this interaction in vivo.

2) The first hypothesis proposed for Ngb was that of oxygen transport. This was based on it being a hemoglobin [118], its presence in the retina (which consumes a lot of oxygen) [96, 119, 120], its intercellular location near mitochondria [19], and up-regulation of $\mathrm{Ngb}$ mRNA in response to hypoxia [121, 122], although other studies refute this observation $[123,124]$. However, this hypothesis is not supported by the low concentrations of $\mathrm{Ngb}$ found in vivo, slow oxygen dissociation rate constants, and high oxygen equilibrium affinity constants observed for these proteins [19, 125].

3) Currently, the most popular hypothesis for Ngb function is protection against hypoxia and oxidative stress, probably through a mechanism involving NO scavenging. Reperfusion of tissues following hypoxia is a well-known cause of damage resulting from reactive oxygen species, and $\mathrm{Ngb}$ is suggested to have a neuroprotective effect under such conditions [121, 126-129]. Greenberg and coworkers have shown that expression of $\mathrm{Ngb}$ increases after ischemic stroke and that $\mathrm{Ngb}$ might be a novel target in stroke therapy [130]. A cognate reductase is required for $\mathrm{NO}$ scavenging, and there has been a lot of research directed toward finding one, but none has been identified yet $[46,75,131,132]$. Thus, there is currently no biochemical mechanism to explain how Ngb increases cell survival following ischemia.

Fago and coworkers have proposed a different molecular mechanism for the protective effect of Ngb in cell death induced by hypoxia, based on a fast electron transfer between ferrous $\mathrm{Ngb}$ and ferric cytochrome $c$ [125] and [133]. In this mechanism, Ngb causes rapid reduction of ferric cytochrome $c$, thereby maintaining levels of non-apoptotic ferrous cytochrome $c$ and simultaneously generating ferric Ngb. Raychaudhuri et al. have reported a similar neuroprotective role of $\mathrm{Ngb}$ by way of inhibiting apoptosis [134]. This hypothesis also requires a mechanism for reduction of $\mathrm{Ngb}$, and a candidate reductase, Apoptosis Inducing Factor (AIF), was proposed for this function. However, a direct test of this activity in vitro failed to support a role for AIF in Ngb reduction [131].

\subsection{Cytoglobin}

Cgb is expressed in almost all types of human tissues [2,40], but was first identified in a proteomic screen of conditions activating hepatic stellate cells [135]. Although all other hxHbs have very high oxygen affinity, $\mathrm{Cgb}$ possesses an oxygen affinity comparable to that of $\mathrm{Mb}[40,136]$, and is up-regulated following hypoxia $[95,137]$. Thus, it is possible that $\mathrm{Cgb}$ replaces $\mathrm{Mb}$ function in tissues where the latter is not expressed [138]. In a role similar to one proposed for $\mathrm{Ngb}, \mathrm{Cgb}$ is a possible $\mathrm{NO}$ scavenger for the purpose of fibroblast proliferation [85], or cytoprotection under oxidizing conditions such as ischemic reperfusion injury [139]. Alternatively, others have proposed roles for Cgb in collagen synthesis [95], and tumor suppression [140], but distinct mechanisms for these roles remain to be established.

\subsection{Drosophila hemoglobin}

Dros $\mathrm{Hb}$ is a monomeric globin discovered in the fruit fly, Drosophila melanogaster $[49,141]$. It is present in low concentrations in the tracheal system and the fat body of both larval and adult fly. Early research speculated a role in facilitated oxygen diffusion across tracheal walls for the protein. However, the $\mathrm{Hb}$ expression levels decreased under limiting oxygen conditions making it unlikely to function as an oxygen storage protein [49]. Like Ngb and Cgb, DrosHb is also a candidate for protection against reactive oxygen species produced by oxygen diffused via the trachea, but there is no clear evidence or mechanism supporting this role [142]. 


\subsection{Mollusk nerve $\mathrm{Hb}$}

The nerve $\mathrm{Hb}$ from the bivalve mollusk, S. solidissima is believed to be an oxygen transport protein [41]. Such glial nerve Hbs are common in species exposed to hypoxia, and enable neuronal function under these conditions [143]. These globins enable mollusk neuronal function and survival under low levels of oxygen, either prevalent in natural habitats or under ischemic conditions [144, 145]. This globin has oxygen binding rate constants very similar to the leghemoglobins, and could seemingly transport oxygen effectively as a pentacoordinate $\mathrm{Hb}$. Thus, the role of hexacoordination in its function could be simply to lower the overall affinity to that needed in this specific environment.

\subsection{Globin X}

GlbX is weakly expressed in amphibia and fish [44]. Its primary sequence is longer than other $\mathrm{HxHbs}$, possessing 2530 extra amino acids at both the $\mathrm{N}$ - and C-termini. However, the proximal and distal histidines along with phenylalanine at CD1 position are conserved [43]. GlbX is distantly related to $\mathrm{Ngb}$, but mRNA expression analysis in goldfish has shown that it is not a neuronal protein [44]. The function of this globin is still unknown (hence the name "Globin X").

\subsection{Caudina arenicola Chain C}

The sea cucumber Caudina arenicola has four different globin chains, which together facilitate cooperative oxygen transport. The mechanism of cooperativity is not completely understood, but appears to involve changes in heteromeric quaternary structure linked to ligand binding [45]. In spite of very high sequence similarity among these chains, only the "Chain $C$ " subunit is hexacoordinate. When first discovered in the absence of other known hxHbs, this observation could have been considered an aberrant conformation resulting from experimental conditions, or an alternative conformation rarely occupied in vivo (such as the case with low-pH human a chains). However, it is also possible that hexacoordination plays a role in these systems, as proposed for human a chains, where it could help to maintain ferrous heme iron by facilitating reduction [146].

\subsection{Plant nsHbs}

Class $1 \mathrm{nsHbs}$ are expressed at low levels in root tissues and have high oxygen affinities with low dissociation rate constants, indicating that they are unlikely to serve as oxygen transport proteins $[4,22]$. Robert Hill and coworkers have proposed a function for Class $1 \mathrm{nsHbs}$ in the maintenance of redox and energy status in plant cells under hypoxia $[147,148]$. Cells expressing Class $1 \mathrm{nsHb}$ display elevated ATP levels, low accumulation of NO, and decreased cell death under hypoxia [149]. NOD function has also been explored for these $\mathrm{Hbs}[75,82,150]$, and the rate of NADH-dependent reduction is enhanced by cytosolic monodehydroascorbate reductase, a likely cognate reductase in vivo [86]. Much less is known about Class 2 and Class 3 nsHbs. It has been shown that, similar to Class $1 \mathrm{nsHb}$, over-expression of Class $2 \mathrm{nsHb}$ increases cell survival during hypoxia. Class $2 \mathrm{Hbs}$ exhibit tighter hexacoordination than Class $1 \mathrm{nsHbs}$ and thus have lower oxygen affinities, increasing the likelihood of possible roles in sensing sustained low levels of oxygen [25, 151].

Class $3 \mathrm{nsHb}$ are found in most plant genomes, with expression reported to be in root and shoot tissues, and downregulated during hypoxia $[33,152]$. A Class $3 \mathrm{nsHb}$ from Arabidopsis shows transient hexacoordination upon reduction, and has unusual ligand binding kinetics [33]. However, these properties have not yet been examined in much detail, and there has been little discussion of potential physiological roles for this class of proteins. Further characterization is needed to determine if the "2-on-2" structural motif observed in their prokaryotic homologous is present in the plant proteins, even though their primary sequences are longer than the "truncated" versions found in bacteria.

\subsection{SynHb}

$\mathrm{Syn} \mathrm{Hb}$ has been shown to have a nitric oxide scavenging function in vitro [75]. However, a reductase remains to be characterized in order to sustain the reaction in vivo. Large structural motions on ligand binding suggest that $S y n \mathrm{Hb}$ might play a role in signaling mechanisms, as has been proposed for human Ngb [114, 115]. An enzymatic role in oxidation-reduction chemistry has also been proposed based on the hydrogen bond networks in the crystal structure [93].

\section{Which came first, pentacoordinate or hexacoordinate Hbs?}

The globins found in prokaryotes, eukaryotes, and archaea are believed to have evolved from a common ancestor with a function unrelated to oxygen transport [143]. Whether this primordial $\mathrm{Hb}$ was of the "3-on-3" or the "2-on-2" structural variety, and whether its coordination state was pentacoordinate or hexacoordinate is unknown. In fact, examination of Figures 2 and 3 suggests a difference in coordination state for the progenitors of plant and animal $\mathrm{Hbs}$, respectively. In plants, pentacoordinate oxygen transporters have evolved from hexacoordinate $\mathrm{Hbs}$ in both Class 1 and Class 2 nsHbs [4, 153], and there are no examples of $\mathrm{hxHbs}$ evolving from pentacoordinate proteins. By contrast, all animal hxHbs evolved from a pentacoordinate ancestral state. In fact, phylogenetic evidence indicates that evolutionary transitions from an ancestral pentacoordinate state to a derived hexacoordinate state have occurred four times independently (Figure 3). As the tree in Figure 3 illustrates, Dro$\mathrm{sHb}, \mathrm{nHb}$ of mollusks, $\mathrm{Cgb}$ of gnathostome vertebrates, and the Ngbs of all animals have each independently evolved hexacoordination from different ancestral starting points. There is no evidence of pentacoordinate $\mathrm{Hbs}$ arising from $\mathrm{hxHbs}$ in the metazoan phylogeny. However, the predominance of pentacoordinate $\mathrm{Hbs}$ in bacteria suggests that this coordination state has existed far longer than it has served as a scaffold for oxygen transport. Therefore, $\mathrm{h} x \mathrm{Hbs}$ could very well have evolved from pentacoordinate Hbs in contrast to earlier suggestions [22, 106].

\section{Conclusions}

The discovery of reversible histidine coordination and exogenous ligand binding in Hbs was surprising in light of the relative inertness of cytochrome $b 5$. The structures of hxHbs in the hexacoordinate and ligand-bound states have revealed different mechanisms for achieving histidine dissociation from the ligand binding site, ranging from the large conformational changes observed in $\mathrm{SynHb}$ to modest repositioning of the heme in $\mathrm{Ngb}$. The conformational changes accompanying ligand binding in $\mathrm{Syn} \mathrm{Hb}$ and rice $\mathrm{nsHb}$ are relatively large, indicating a degree of flexibility in the globin fold that was not anticipated from previous globin structures. These conformational changes could be a component of the mechanism of action of hxHbs, or a structural necessity for reversible ligand binding; an answer to this question must await identification of physiological function(s).

It was first thought that, in general, pentacoordinate $\mathrm{Hbs}$ evolved from hxHbs. This makes sense from a structural perspective; a distal histidine nearby but not coordinating the heme iron would be difficult to stabilize in a flexible globin. It was logical to consider that pentacoordinate $\mathrm{Hbs}$ evolved from $\mathrm{hxHbs}$ by stabilizing the pentacoordinate conformation of the $\mathrm{h} \times \mathrm{Hb}$, and reducing the flexibility of the globin to lock it into only this conformation. However, the animal $\mathrm{Hb}$ phylogeny does not support this conclusion, showing instead that pentacoordinate $\mathrm{Hbs}$ predate hxHbs in animals. This is an impor- 
tant consideration as it suggests selection for a hexacoordinate heme center and the accompanying chemistry and potential conformational variability. It is thus likely that these properties will be linked to function, and should be carefully considered as these physiological activities are identified.

Based on the current description of hxHbs, it seems likely that their function(s) involve 1) exogenous ligand binding, 2) a change in heme iron oxidation state, and 3) a role in signaling. These conclusions are based on the following observations, respectively. 1) Hexacoordination and affinity for exogenous ligands is conserved across each group of hxHbs, and even across the classes of plant nsHbs. 2) Hexacoordination facilitates electron transfer. If the goal were simply to bind and release ligands, a pentacoordinate heme would be preferred (as in oxygen transport $\mathrm{Hbs}$ ). 3) $\mathrm{HxHbs}$ are present in very low concentrations, and ligand binding could trigger conformational and redox changes that regulate interactions with other signaling molecules.

Identification of the function of proteins is the next frontier of biochemistry, and is certainly the rate-limiting step in our understanding of hxHbs. The magnitude of this problem is realized by considering the difficulty that would face researchers trying to discover the function of the red blood cell $\mathrm{Hb}$ subunits using only recombinant proteins in the laboratory. The behavior of these isolated chains reflects that of native $\mathrm{Hb}$ in some ways, but could also lead down many false paths. This is the situation with hxHbs, where the results from in vitro experiments are certainly telling us something about physiological function, but are also providing much more information than can be assimilated into clear hypothesis in the background of a much smaller number of physiological studies. A confident interpretation of biochemistry will only come from its ability to explain a clear physiological function.

\section{References}

[1] T. Hankeln, B. Ebner, C. Fuchs, F. Gerlach, M. Haberkamp, T. Laufs, A. Roesner, M. Schmidt, B. Weich, S. Wystub, S. Saaler-Reinhardt, S. Reuss, M. Bolognesi, D. De Sanctis, M. Marden, L. Kiger, L. Moens, S. Dewilde, E. Nevo, A. Avivi, R. Weber, A. Fago and T. Burmester, Neuroglobin and cytoglobin in search of their role in the vertebrate globin family, J. Inorg. Biochem. 99 (2005), pp. 110-119.

[2] T. Burmester, B. Ebner, B. Weich and T. Hankeln, Cytoglobin: a novel globin type ubiquitously expressed in vertebrate tissues, Mol. Biol. Evol. 19 (2002), pp. 416-421.

[3] J. Wittenberg, M. Bolognesi, B. Wittenberg and M. Guertin, Truncated hemoglobins: a new family of hemoglobins widely distributed in bacteria, unicellular eukaryotes, and plants, J. Biol. Chem. 277 (2002), pp. 871-874.

[4] B. Smagghe, J. Hoy, R. Percifield, S. Kundu, M. Hargrove, G. Sarath, J. Hilbert, R. Watts, E. Dennis, W. Peacock, S. Dewilde, L. Moens, G. Blouin, J. Olson and C. Appleby, Review: correlations between oxygen affinity and sequence classifications of plant hemoglobins, Biopolymers 91 (2009), pp. 1083-1096.

[5] J. Murray, O. Delumeau and R. Lewis, Structure of a nonheme globin in environmental stress signaling, Proc. Natl. Acad. Sci. U. S. A. 102 (2005), pp. 17320-17325.

[6] L. Smith, A. Kahraman and J. Thornton, Heme proteins - diversity in structural characteristics, function, and folding, Proteins 78 (2010), pp. 2349-2368.

[7] E. Derbyshire and M. Marletta, Biochemistry of soluble guanylate cyclase, Handb. Exp. Pharmacol. (2009), pp. 17-31.

[8] E. Boon and M. Marletta, Ligand discrimination in soluble guanylate cyclase and the H-NOX family of heme sensor proteins, Curr. Opin. Chem. Biol. 9 (2005), pp. 441-446.

[9] D. Lawson, C. Stevenson, C. Andrew and R. Eady, Unprecedented proximal binding of nitric oxide to heme: implications for guanylate cyclase, EMBO J. 19 (2000), pp. 5661-5671.

[10] T.G. Traylor and V.S. Sharma, Why NO?, Biochemistry 31 (1992), pp. 2847-2849.

[11] R. Hille, J.S. Olson and G. Palmer, Spectral transitions of nitrosyl hemes during ligand binding to hemoglobin, J. Biol. Chem. 254 (1979), pp. 12110-12120.

[12] A. Duprat, T. Traylor, G. Wu, M. Coletta, V. Sharma, K. Walda and D. Magde, Myoglobin-NO at low pH: free four-coordinated heme in the protein pocket, Biochemistry 34 (1995), pp. 2634-2644.

[13] S. Zhou, J. Olson, M. Fabian, M. Weiss and A. Gow, Biochemical fates of alpha hemoglobin bound to alpha hemoglobin-stabilizing protein AHSP, J. Biol. Chem. 281 (2006), pp. 32611-32618.

[14] S. Hua, S. Antao, A. Corbett and P. Witting, The significance of neuroglobin in the brain, Curr. Med. Chem. 17 (2010), pp. 160-172.

[15] S. Herold, A. Fago, R. Weber, S. Dewilde and L. Moens, Reactivity studies of the $\mathrm{Fe}(\mathrm{III})$ and $\mathrm{Fe}(\mathrm{II}) \mathrm{NO}$ forms of human neuroglobin reveal a potential role against oxidative stress, J. Biol. Chem. 279 (2004), pp. 22841-22847.

[16] P. Witting, D. Douglas and A. Mauk, Reaction of human myoglobin and $\mathrm{H} 2 \mathrm{O} 2$. Involvement of a thiyl radical produced at cysteine 110, J. Biol. Chem. 275 (2000), pp. 20391-20398.

[17] J.R. Trent, R. Watts and M. Hargrove, Human neuroglobin, a hexacoordinate hemoglobin that reversibly binds oxygen, J. Biol. Chem. 276 (2001), pp. 30106-30110.

[18] S. Duff, J. Wittenberg and R. Hill, Expression, purification, and properties of recombinant barley (Hordeum sp.) hemoglobin. Optical spectra and reactions with gaseous ligands, J. Biol. Chem. 272 (1997), pp. 16746-16752.

[19] T. Burmester, B. Weich, S. Reinhardt and T. Hankeln, A vertebrate globin expressed in the brain, Nature 407 (2000), pp. 520-523.

[20] N. Scott and J. Lecomte, Cloning, expression, purification, and preliminary characterization of a putative hemoglobin from the cyanobacterium Synechocystis sp. PCC 6803, Protein Sci. 9 (2000), pp. 587-597.

[21] C. Appleby, J. Tjepkema and M. Trinick, Hemoglobin in a nonleguminous plant, parasponia: possible genetic origin and function in nitrogen fixation, Science 220 (1983), pp. 951-953

[22] S. Kundu, J.r. Trent and M. Hargrove, Plants, humans and hemoglobins, Trends Plant Sci. 8 (2003), pp. 387-393.

[23] D. Bogusz, C. Appleby, J. Landsmann, E. Dennis, M. Trinick and W. Peacock, Functioning haemoglobin genes in non-nodulating plants, Nature 331 (1988), pp. 178-180.

[24] R. Arredondo-Peter, M. Hargrove, G. Sarath, J. Moran, J. Lohrman, J. Olson and R. Klucas, Rice hemoglobins. Gene cloning, analysis, and O2-binding kinetics of a recombinant protein synthesized in Escherichia coli, Plant Physiol. 115 (1997), pp. 1259-1266.

[25] S. Bruno, S. Faggiano, F. Spyrakis, A. Mozzarelli, S. Abbruzzetti, E. Grandi, C. Viappiani, A. Feis, S. Mackowiak, G. Smulevich, E. Cacciatori and P. Dominici, The reactivity with $\mathrm{CO}$ of $\mathrm{AHb} 1$ and $\mathrm{AHb} 2$ from Arabidopsis thaliana is controlled by the distal HisE7 and internal hydrophobic cavities, $J$. Am. Chem. Soc. 129 (2007), pp. 2880-2889.

[26] K. Yamauchi, H. Tada and I. Usuki, Structure and evolution of Paramecium hemoglobin genes, Biochim. Biophys. Acta 1264 (1995), pp. 53-62.

[27] H. Iwaasa, T. Takagi and K. Shikama, Protozoan myoglobin from Paramecium caudatum. Its unusual amino acid sequence, J. Mol. Biol. 208 (1989), pp. 355-358.

[28] H. Iwaasa, T. Takagi and K. Shikama, Protozoan hemoglobin from Tetrahymena pyriformis. Isolation, characterization, and amino acid sequence., J. Biol. Chem. 265 (1990), pp. 8603-8609.

[29] T. Takagi, H. Iwaasa, H. Yuasa, K. Shikama, T. Takemasa and Y. Watanabe, Primary structure of Tetrahymena hemoglobins, Biochim. Biophys. Acta 1173 (1993), pp. 75-78.

[30] M. Potts, S. Angeloni, R. Ebel and D. Bassam, Myoglobin in a cyanobacterium, Science 256 (1992), pp. 1690-1691.

[31] M. Couture, T. Das, H. Lee, J. Peisach, D. Rousseau, B. Wittenberg, J. Wittenberg and M. Guertin, Chlamydomonas chloroplast ferrous hemoglobin. Heme pocket structure and reactions with ligands, J. Biol. Chem. 274 (1999), pp. 6898-6910.

[32] M. Couture, S. Yeh, B. Wittenberg, J. Wittenberg, Y. Ouellet, D. Rousseau and M. Guertin, A cooperative oxygen-binding hemoglobin from Mycobacterium tuberculosis, Proc. Natl. Acad. Sci. U. S. A. 96 (1999), pp. 11223-11228.

[33] R. Watts, P. Hunt, A. Hvitved, M. Hargrove, W. Peacock and E. Dennis, A hemoglobin from plants homologous to truncated hemoglobins of microorganisms, Proc. Natl. Acad. Sci. U. S. A. 98 (2001), pp. 10119-10124.

[34] S. Vinogradov, D. Hoogewijs, X. Bailly, R. Arredondo-Peter, M. Guertin, J. Gough, S. Dewilde, L. Moens and J. Vanfleteren, Three globin lineages belonging to two structural classes in genomes from the three kingdoms of life, Proc. Natl. Acad. Sci. U. S. A. 102 (2005), pp. 11385-11389.

[35] A. Hvitved, J.r. Trent, S. Premer and M. Hargrove, Ligand binding and hexacoordination in synechocystis hemoglobin, J. Biol. Chem. 276 (2001), pp 34714-34721.

[36] M. Couture, T. Das, P. Savard, Y. Ouellet, J. Wittenberg, B. Wittenberg, D. Rousseau and M. Guertin, Structural investigations of the hemoglobin of the cyanobacterium Synechocystis PCC6803 reveal a unique distal heme pocket, Eur. J. Biochem. 267 (2000), pp. 4770-4780.

[37] J. Hoy, S. Kundu, J.r. Trent, S. Ramaswamy and M. Hargrove, The crystal structure of Synechocystis hemoglobin with a covalent heme linkage, I. Biol. Chem. 279 (2004), pp. 16535-16542.

[38] B. Vu, A. Jones and J. Lecomte, Novel histidine-heme covalent linkage in a hemoglobin, J. Am. Chem. Soc. 124 (2002), pp. 8544-8545

[39] C. Fuchs, V. Heib, L. Kiger, M. Haberkamp, A. Roesner, M. Schmidt, D. Hamdane, M. Marden, T. Hankeln and T. Burmester, Zebrafish reveals different and conserved features of vertebrate neuroglobin gene structure, expression pattern, and ligand binding, J. Biol. Chem. 279 (2004), pp. $24116-24122$.

[40] J.r. Trent and M. Hargrove, A ubiquitously expressed human hexacoordinate hemoglobin, J. Biol. Chem. 277 (2002), pp. 19538-19545.

[41] S. Dewilde, B. Ebner, E. Vinck, K. Gilany, T. Hankeln, T. Burmester, J. Kreiling, C. Reinisch, J. Vanfleteren, L. Kiger, M. Marden, C. Hundahl, A. Fago, $\mathrm{S}$. Van Doorslaer and L. Moens, The nerve hemoglobin of the bivalve mollusc Spisula solidissima: molecular cloning, ligand binding studies, and phylogenetic analysis, J. Biol. Chem. 281 (2006), pp. 5364-5372

[42] D. de Sanctis, S. Dewilde, C. Vonrhein, A. Pesce, L. Moens, P. Ascenzi, T. Hankeln, T. Burmester, M. Ponassi, M. Nardini and M. Bolognesi, Bishistidyl heme hexacoordination, a key structural property in Drosophila melanogaster hemoglobin, J. Biol. Chem. 280 (2005), pp. 27222-27229.

[43] C. Fuchs, T. Burmester and T. Hankeln, The amphibian globin gene repertoire as revealed by the Xenopus genome, Cytogenet. Genome Res. 112 (2006), pp. 296-306. 
[44] A. Roesner, C. Fuchs, T. Hankeln and T. Burmester, A globin gene of ancient evolutionary origin in lower vertebrates: evidence for two distinct globin families in animals, Mol. Biol. Evol. 22 (2005), pp. 12-20.

[45] D. Mitchell, G. Kitto and M. Hackert, Structural analysis of monomeric hemichrome and dimeric cyanomet hemoglobins from Caudina arenicola, $J$. Mol. Biol. 251 (1995), pp. 421-431.

[46] S. Dewilde, L. Kiger, T. Burmester, T. Hankeln, V. Baudin-Creuza, T. Aerts, M. Marden, R. Caubergs and L. Moens, Biochemical characterization and ligand binding properties of neuroglobin, a novel member of the globin family, J. Biol. Chem. 276 (2001), pp. 38949-38955.

[47] D. Hamdane, L. Kiger, S. Dewilde, B. Green, A. Pesce, J. Uzan, T. Burmester, T. Hankeln, M. Bolognesi, L. Moens and M. Marden, The redox state of the cell regulates the ligand binding affinity of human neuroglobin and cytoglobin, J. Biol. Chem. 278 (2003), pp. 51713-51721.

[48] B. Smagghe, G. Sarath, E. Ross, J. Hilbert and M. Hargrove, Slow ligand binding kinetics dominate ferrous hexacoordinate hemoglobin reactivities and reveal differences between plants and other species, Biochemistry 45 (2006), pp. 561-570.

[49] T. Hankeln, V. Jaenicke, L. Kiger, S. Dewilde, G. Ungerechts, M. Schmidt, J. Urban, M. Marden, L. Moens and T. Burmester, Characterization of Drosophila hemoglobin. Evidence for hemoglobin-mediated respiration in insects., J. Biol. Chem. 277 (2002), pp. 29012-29017.

[50] E. Antonini and M. Brunori, Hemoglobin and Myoglobin in Their Reactions with Ligands, North-Holland Publishing Company, Amsterdam (1971).

[51] J. Peisach, W. Blumberg, B. Wittenberg, J. Wittenberg and L. Kampa, Hemoglobin A: an electron paramagnetic resonance study of the effects of interchain contacts on the heme symmetry of high-spin and low-spin derivatives of ferric alpha chains, Proc. Natl. Acad. Sci. U. S. A. 63 (1969), pp. 934-939.

[52] P. Halder, J.r. Trent and M. Hargrove, Influence of the protein matrix on intramolecular histidine ligation in ferric and ferrous hexacoordinate hemoglobins, Proteins 66 (2007), pp. 172-182.

[53] Y. Dou, S. Admiraal, M. Ikeda-Saito, S. Krzywda, A. Wilkinson, T. Li, J. Olson, R. Prince, I. Pickering and G. George, Alteration of axial coordination by protein engineering in myoglobin. Bisimidazole ligation in the His64>Val/Val68->His double mutant, J. Biol. Chem. 270 (1995), pp. 15993-16001.

[54] M. Hargrove, A flash photolysis method to characterize hexacoordinate hemoglobin kinetics, Biophys. J. 79 (2000), pp. 2733-2738.

[55] A. Brancaccio, F. Cutruzzolá, C. Allocatelli, M. Brunori, S. Smerdon, A. Wilkinson, Y. Dou, D. Keenan, M. Ikeda-Saito and R.J. Brantley, Structural factors governing azide and cyanide binding to mammalian metmyoglobins, J. Biol. Chem. 269 (1994), pp. 13843-13853.

[56] M. Coletta, M. Angeletti, G. De Sanctis, L. Cerroni, B. Giardina, G. Amiconi and P. Ascenzi, Kinetic evidence for the existence of a rate-limiting step in the reaction of ferric hemoproteins with anionic ligands, Eur. J. Biochem. 235 (1996), pp. 49-53.

[57] B. Smagghe, P. Halder and M. Hargrove, Measurement of distal histidine coordination equilibrium and kinetics in hexacoordinate hemoglobins, Methods Enzymol. 436 (2008), pp. 359-378.

[58] R.J. Brantley, S. Smerdon, A. Wilkinson, E. Singleton and J. Olson, The mechanism of autooxidation of myoglobin, J. Biol. Chem. 268 (1993), pp. 6995-7010.

[59] J. Olson and G.J. Phillips, Kinetic pathways and barriers for ligand binding to myoglobin, J. Biol. Chem. 271 (1996), pp. 17593-17596.

[60] E. Liong, Y. Dou, E. Scott, J. Olson and G.J. Phillips, Waterproofing the heme pocket. Role of proximal amino acid side chains in preventing hemin loss from myoglobin, J. Biol. Chem. 276 (2001), pp. 9093-9100.

[61] R.t. Aranda, H. Cai, C. Worley, E. Levin, R. Li, J. Olson, G.J. Phillips and M. Richards, Structural analysis of fish versus mammalian hemoglobins: effect of the heme pocket environment on autooxidation and hemin loss, Proteins 75 (2009), pp. 217-230.

[62] J. Murray and J. Wyman, Facilitated diffusion. The case of carbon monoxide, J. Biol. Chem. 246 (1971), pp. 5903-5906.

[63] Q. Gibson, J. Wittenberg, B. Wittenberg, D. Bogusz and C. Appleby, The kinetics of ligand binding to plant hemoglobins. Structural implications, J. Biol. Chem. 264 (1989), pp. 100-107.

[64] J. Wittenberg, C. Appleby and B. Wittenberg, The kinetics of the reactions of leghemoglobin with oxygen and carbon monoxide, J. Biol. Chem. 247 (1972), pp. 527-531.

[65] T. Weiland, S. Kundu, J.R. Trent, J. Hoy and M. Hargrove, Bis-histidyl hexacoordination in hemoglobins facilitates heme reduction kinetics, J. Am. Chem. Soc. 126 (2004), pp. 11930-11935.

[66] M. Russwurm and D. Koesling, NO activation of guanylyl cyclase, EMBO J. 23 (2004), pp. 4443-4450.

[67] L. Ignarro, Haem-dependent activation of guanylate cyclase and cyclic GMP formation by endogenous nitric oxide: a unique transduction mechanism for transcellular signaling, Pharmacol. Toxicol. 67 (1990), pp. 1-7.

[68] R. Eich, T. Li, D. Lemon, D. Doherty, S. Curry, J. Aitken, A. Mathews, K. Johnson, R. Smith, G.J. Phillips and J. Olson, Mechanism of NO-induced oxidation of myoglobin and hemoglobin, Biochemistry 35 (1996), pp. 6976-6983.

[69] M. Brunori, Nitric oxide, cytochrome-c oxidase and myoglobin, Trends Biochem. Sci. 26 (2001), pp. 21-23.

[70] P. Gardner, Nitric oxide dioxygenase function and mechanism of flavohemoglobin, hemoglobin, myoglobin and their associated reductases, J. Inorg. Biochem. 99 (2005), pp. 247-266.

[71] P. Gardner, A. Gardner, L. Martin and A. Salzman, Nitric oxide dioxygenase: an enzymic function for flavohemoglobin, Proc. Natl. Acad. Sci. U. S. A. 95 (1998), pp. 10378-10383. | Cited By in Scopus (251)

[72] A. Gow, B. Luchsinger, J. Pawloski, D. Singel and J. Stamler, The oxyhemoglobin reaction of nitric oxide, Proc. Natl. Acad. Sci. U. S. A. 96 (1999), pp.
9027-9032

[73] P. Gardner, A. Gardner, W. Brashear, T. Suzuki, A. Hvitved, K. Setchell and J. Olson, Hemoglobins dioxygenate nitric oxide with high fidelity, J. Inorg. Biochem. 100 (2006), pp. 542-550.

[74] S. Van Doorslaer, S. Dewilde, L. Kiger, S. Nistor, E. Goovaerts, M. Marden and L. Moens, Nitric oxide binding properties of neuroglobin. A characterization by EPR and flash photolysis, J. Biol. Chem. 278 (2003), pp. 4919-4925.

[75] B. Smagghe, J.r. Trent and M. Hargrove, NO dioxygenase activity in hemoglobins is ubiquitous in vitro, but limited by reduction in vivo, PLoS One 3 (2008), p. e2039.

[76] P. Ford, B. Fernandez and M. Lim, Mechanisms of reductive nitrosylation in iron and copper models relevant to biological systems, Chem. Rev. 105 (2005), pp. 2439-2455.

[77] B. Fernandez, I. Lorkovic and P. Ford, Mechanisms of ferriheme reduction by nitric oxide: nitrite and general base catalysis, Inorg. Chem. 43 (2004), pp. 5393-5402.

[78] M. Hoshino, M. Masahiro, K. Reiko, H. Seki and C. Ford Peter, Studies on the reaction mechanism for reductive nitrosylation of ferrihemoproteins in buffer solutions, J. Am. Chem. Soc. 118 (1996), pp. 5702-5707.

[79] M. Brunori, A. Giuffrè, K. Nienhaus, G. Nienhaus, F. Scandurra and B. Vallone, Neuroglobin, nitric oxide, and oxygen: functional pathways and conformational changes, Proc. Natl. Acad. Sci. U. S. A. 102 (2005), pp. 8483-8488.

[80] M. Perazzolli, M. Romero-Puertas and M. Delledonne, Modulation of nitric oxide bioactivity by plant haemoglobins, J. Exp. Bot. 57 (2006), pp. 479-488.

[81] D. Minning, A. Gow, J. Bonaventura, R. Braun, M. Dewhirst, D. Goldberg and J. Stamler, Ascaris haemoglobin is a nitric oxide-activated 'deoxygenase', Nature 401 (1999), pp. 497-502.

[82] M. Perazzolli, P. Dominici, M. Romero-Puertas, E. Zago, J. Zeier, M. Sonoda, C. Lamb and M. Delledonne, Arabidopsis nonsymbiotic hemoglobin AHb1 modulates nitric oxide bioactivity, Plant Cell 16 (2004), pp. 2785-2794.

[83] C. Dordas, B. Hasinoff, J. Rivoal and R. Hill, Class-1 hemoglobins, nitrate and NO levels in anoxic maize cell-suspension cultures, Planta 219 (2004), pp. 66-72.

[84] M. Delledonne, NO news is good news for plants, Curr. Opin. Plant Biol. 8 (2005), pp. 390-396

[85] K. Halligan, F. Jourd'heuil and D. Jourd'heuil, Cytoglobin is expressed in the vasculature and regulates cell respiration and proliferation via nitric oxide dioxygenation, J. Biol. Chem. 284 (2009), pp. 8539-8547.

[86] A. Igamberdiev, N. Bykova and R. Hill, Nitric oxide scavenging by barley hemoglobin is facilitated by a monodehydroascorbate reductase-mediated ascorbate reduction of methemoglobin, Planta 223 (2006), pp. 1033-1040.

[87] D. de Sanctis, S. Dewilde, A. Pesce, L. Moens, P. Ascenzi, T. Hankeln, T. Burmester and M. Bolognesi, Crystal structure of cytoglobin: the fourth globin type discovered in man displays heme hexa-coordination, J. Mol. Biol. 336 (2004), pp. 917-927.

[88] B. Vallone, K. Nienhaus, M. Brunori and G. Nienhaus, The structure of murine neuroglobin: novel pathways for ligand migration and binding, Proteins 56 (2004), pp. 85-92.

[89] B. Vallone, K. Nienhaus, A. Matthes, M. Brunori and G. Nienhaus, The structure of carbonmonoxy neuroglobin reveals a heme-sliding mechanism for control of ligand affinity, Proc. Natl. Acad. Sci. U. S. A. 101 (2004), pp. 17351-17356.

[90] D. de Sanctis, P. Ascenzi, A. Bocedi, S. Dewilde, T. Burmester, T. Hankeln, L. Moens and M. Bolognesi, Cyanide binding and heme cavity conformational transitions in Drosophila melanogaster hexacoordinate hemoglobin Biochemistry 45 (2006), pp. 10054-10061.

[91] M. Hargrove, E. Brucker, B. Stec, G. Sarath, R. Arredondo-Peter, R. Klucas, J. Olson and G.J. Phillips, Crystal structure of a nonsymbiotic plant hemoglobin, Structure 8 (2000), pp. 1005-1014.

[92] J. Hoy, H. Robinson, J.r. Trent, S. Kakar, B. Smagghe and M. Hargrove, Plant hemoglobins: a molecular fossil record for the evolution of oxygen transport, J. Mol. Biol. 371 (2007), pp. 168-179.

[93] J.R. Trent, S. Kundu, J. Hoy and M. Hargrove, Crystallographic analysis of synechocystis cyanoglobin reveals the structural changes accompanying ligand binding in a hexacoordinate hemoglobin, J. Mol. Biol. 341 (2004), pp. 1097-1108.

[94] J. Yoon, M. Herzik, M. Winter, R. Tran, C. Olea and M. Marletta, Structure and properties of a bis-histidyl ligated globin from Caenorhabditis elegans, Biochemistry 49 (2010), pp. 5662-5670.

[95] M. Schmidt, F. Gerlach, A. Avivi, T. Laufs, S. Wystub, J. Simpson, E. Nevo, S. Saaler-Reinhardt, S. Reuss, T. Hankeln and T. Burmester, Cytoglobin is a respiratory protein in connective tissue and neurons, which is up-regulated by hypoxia, J. Biol. Chem. 279 (2004), pp. 8063-8069.

[96] J. Ostojić, D. Sakaguchi, Y. de Lathouder, M. Hargrove, J.r. Trent, Y. Kwon, R. Kardon, M. Kuehn, D. Betts and S. Grozdanić, Neuroglobin and cytoglobin: oxygen-binding proteins in retinal neurons., Invest. Ophthalmol. Vis. Sci. 47 (2006), pp. 1016-1023.

[97] M. Schmidt, T. Laufs, S. Reuss, T. Hankeln and T. Burmester, Divergent distribution of cytoglobin and neuroglobin in the murine eye, Neurosci. Lett 374 (2005), pp. 207-211.

[98] M. Goodman and M. Hargrove, Quaternary structure of rice nonsymbiotic hemoglobin, J. Biol. Chem. 276 (2001), pp. 6834-6839.

[99] A. Fago, C. Hundahl, S. Dewilde, K. Gilany, L. Moens and R. Weber, Allosteric regulation and temperature dependence of oxygen binding in human neuroglobin and cytoglobin. Molecular mechanisms and physiological significance., J. Biol. Chem. 279 (2004), pp. 44417-44426.

[100] A. Pesce, M. Couture, S. Dewilde, M. Guertin, K. Yamauchi, P. Ascenzi, L. Moens and M. Bolognesi, A novel two-over-two alpha-helical sandwich fold is characteristic of the truncated hemoglobin family, EMBO J. 19 (2000), pp. 2424-2434. 
[101] M. Laberge and T. Yonetani, Common dynamics of globin family proteins, IUBMB Life 59 (2007), pp. 528-534.

[102] D. de Sanctis, A. Pesce, M. Nardini, M. Bolognesi, A. Bocedi and P. Ascenzi, Structure-function relationships in the growing hexa-coordinate hemoglobin sub-family, IUBMB Life 56 (2004), pp. 643-651.

[103] S. Van Doorslaer, E. Vinck, F. Trandafir, I. Ioanitescu, S. Dewilde and L. Moens, Tracing the structure-function relationship of neuroglobin and cytoglobin using resonance Raman and electron paramagnetic resonance spectroscopy, IUBMB Life 56 (2004), pp. 665-670.

[104] W. Du, R. Syvitski, S. Dewilde, L. Moens and G. La Mar, Solution 1 h NMR characterization of equilibrium heme orientational disorder with functional consequences in mouse neuroglobin, J. Am. Chem. Soc. 125 (2003), pp. 8080-8081.

[105] F. Walker, The heme environment of mouse neuroglobin: histidine imidazole plane orientations obtained from solution NMR and EPR spectroscopy as compared with X-ray crystallography, J. Biol. Inorg. Chem. 11 (2006), pp. 391-397.

[106] M. Brunori and B. Vallone, Neuroglobin, seven years after, Cell. Mol. Life Sci. 64 (2007), pp. 1259-1268.

[107] E. Vinck, S. Van Doorslaer, S. Dewilde, G. Mitrikas, A. Schweiger and L. Moens, Analyzing heme proteins using EPR techniques: the heme-pocket structure of ferric mouse neuroglobin, J. Biol. Inorg. Chem. 11 (2006), pp. $467-475$.

[108] E. Vinck, S. Van Doorslaer, S. Dewilde and L. Moens, Structural change of the heme pocket due to disulfide bridge formation is significantly larger for neuroglobin than for cytoglobin, J. Am. Chem. Soc. 126 (2004), pp. 4516-4517.

[109] R. Durley and F. Mathews, Refinement and structural analysis of bovine cytochrome b5 at 1.5 A resolution, Acta Crystallogr. D Biol. Crystallogr. 52 (1996), pp. 65-76.

[110] Z. Xu and R. Farid, Design, synthesis, and characterization of a novel hemoprotein, Protein Sci. 10 (2001), pp. 236-249.

[111] A. Pesce, S. Dewilde, M. Nardini, L. Moens, P. Ascenzi, T. Hankeln, T. Burmester and M. Bolognesi, Human brain neuroglobin structure reveals a distinct mode of controlling oxygen affinity, Structure 11 (2003), pp. 1087-1095.

[112] M. Hargrove, J. Barry, E. Brucker, M. Berry, G.J. Phillips, J. Olson, R. Arredondo-Peter, J. Dean, R. Klucas and G. Sarath, Characterization of recombinant soybean leghemoglobin a and apolar distal histidine mutants, $J$. Mol. Biol. 266 (1997), pp. 1032-1042.

[113] T. Burmester and T. Hankeln, What is the function of neuroglobin?, J. Exp. Biol. 212 (2009), pp. 1423-1428.

[114] K. Wakasugi, T. Nakano and I. Morishima, Oxidized human neuroglobin acts as a heterotrimeric Galpha protein guanine nucleotide dissociation inhibitor, J. Biol. Chem. 278 (2003), pp. 36505-36512.

[115] K. Wakasugi and I. Morishima, Identification of residues in human neuroglobin crucial for Guanine nucleotide dissociation inhibitor activity, Biochemistry 44 (2005), pp. 2943-2948.

[116] J. Lewerenz, J. Letz and A. Methner, Activation of stimulatory heterotrimeric $\mathrm{G}$ proteins increases glutathione and protects neuronal cells against oxidative stress, J. Neurochem. 87 (2003), pp. 522-531.

[117] K. Wakasugi, C. Kitatsuji and I. Morishima, Possible neuroprotective mechanism of human neuroglobin, Ann. N.Y. Acad. Sci. 1053 (2005), pp. $220-230$.

[118] L. Moens and S. Dewilde, Globins in the brain, Nature 407 (2000), pp. 461-462.

[119] T. Burmester and T. Hankeln, Neuroglobin: a respiratory protein of the nervous system, News Physiol. Sci. 19 (2004), pp. 110-113.

[120] M. Schmidt, A. Giessl, T. Laufs, T. Hankeln, U. Wolfrum and T. Burmester, How does the eye breathe? Evidence for neuroglobin-mediated oxygen supply in the mammalian retina, J. Biol. Chem. 278 (2003), pp. 1932-1935.

[121] Y. Sun, K. Jin, X. Mao, Y. Zhu and D. Greenberg, Neuroglobin is up-regulated by and protects neurons from hypoxic-ischemic injury, Proc. Natl. Acad. Sci. U. S. A. 98 (2001), pp. 15306-15311.

[122] R. Schmidt-Kastner, M. Haberkamp, C. Schmitz, T. Hankeln and T. Burmester, Neuroglobin mRNA expression after transient global brain ischemia and prolonged hypoxia in cell culture, Brain Res. 1103 (2006), pp. 173-180.

[123] P. Mammen, J. Shelton, S. Goetsch, S. Williams, J. Richardson, M. Garry and D. Garry, Neuroglobin, a novel member of the globin family, is expressed in focal regions of the brain, J. Histochem. Cytochem. 50 (2002), pp. 1591-1598.

[124] C. Hundahl, M. Stoltenberg, A. Fago, R. Weber, S. Dewilde, E. Fordel and G. Danscher, Effects of short-term hypoxia on neuroglobin levels and localization in mouse brain tissues, Neuropathol. Appl. Neurobiol. 31 (2005), pp. 610-617.

[125] A. Fago, A. Mathews and T. Brittain, A role for neuroglobin: resetting the trigger level for apoptosis in neuronal and retinal cells, IUBMB Life $\mathbf{6 0}$ (2008), pp. 398-401.

[126] Y. Sun, K. Jin, A. Peel, X. Mao, L. Xie and D. Greenberg, Neuroglobin protects the brain from experimental stroke in vivo, Proc. Natl. Acad. Sci. U. S. A. 100 (2003), pp. 3497-3500.

[127] X. Wang, J. Liu, H. Zhu, E. Tejima, K. Tsuji, Y. Murata, D. Atochin, P. Huang, C. Zhang and E. Lo, Effects of neuroglobin overexpression on acute brain injury and long-term outcomes after focal cerebral ischemia, Stroke 39 (2008), pp. 1869-1874.

[128] J. Liu, Z. Yu, S. Guo, S. Lee, C. Xing, C. Zhang, Y. Gao, D. Nicholls, E. Lo and X. Wang, Effects of neuroglobin overexpression on mitochondrial function and oxidative stress following hypoxia/reoxygenation in cultured neurons, J. Neurosci. Res. 87 (2009), pp. 164-170.
[129] A. Khan, Y. Wang, Y. Sun, X. Mao, L. Xie, E. Miles, J. Graboski, S. Chen, L. Ellerby, K. Jin and D. Greenberg, Neuroglobin-overexpressing transgenic mice are resistant to cerebral and myocardial ischemia, Proc. Natl. Acad. Sci. U. S. A. 103 (2006), pp. 17944-17948.

[130] K. Jin, Y. Mao, X. Mao, L. Xie and D. Greenberg, Neuroglobin expression in ischemic stroke, Stroke $\mathbf{4 1}$ (2010), pp. 557-559.

[131] T. Moschetti, A. Giuffrè, C. Ardiccioni, B. Vallone, N. Modjtahedi, G. Kroemer and M. Brunori, Failure of apoptosis-inducing factor to act as neuroglobin reductase, Biochem. Biophys. Res. Commun. 390 (2009), pp. 121-124.

[132] F. Trandafir, D. Hoogewijs, F. Altieri, P. Rivetti di Val Cervo, K. Ramser, S. Van Doorslaer, J. Vanfleteren, L. Moens and S. Dewilde, Neuroglobin and cytoglobin as potential enzyme or substrate, Gene 398 (2007), pp. 103-113.

[133] A. Fago, A. Mathews, L. Moens, S. Dewilde and T. Brittain, The reaction of neuroglobin with potential redox protein partners cytochrome b5 and cytochrome c, FEBS Lett. 580 (2006), pp. 4884-4888.

[134] S. Raychaudhuri, J. Skommer, K. Henty, N. Birch and T. Brittain, Neuroglobin protects nerve cells from apoptosis by inhibiting the intrinsic pathway of cell death, Apoptosis 15 (2010), pp. 401-411.

[135] N. Kawada, D. Kristensen, K. Asahina, K. Nakatani, Y. Minamiyama, S. Seki and K. Yoshizato, Characterization of a stellate cell activation-associated protein (STAP) with peroxidase activity found in rat hepatic stellate cells, J. Biol. Chem. 276 (2001), pp. 25318-25323.

[136] B.A. Springer, S.G. Sliger, J.S. Olson and G.N.J. Phillips, Mechanisms of ligand recognition in myoglobin, Chem. Rev. 94 (1994), pp. 699-714.

[137] E. Fordel, E. Geuens, S. Dewilde, P. Rottiers, P. Carmeliet, J. Grooten and L. Moens, Cytoglobin expression is upregulated in all tissues upon hypoxia: an in vitro and in vivo study by quantitative real-time PCR, Biochem. Biophys. Res. Commun. 319 (2004), pp. 342-348.

[138] Y. Xi, M. Obara, Y. Ishida, S. Ikeda and K. Yoshizato, Gene expression and tissue distribution of cytoglobin and myoglobin in the Amphibia and Reptilia: possible compensation of myoglobin with cytoglobin in skeletal muscle cells of anurans that lack the myoglobin gene, Gene 398 (2007), pp. 94-102.

[139] N. Hodges, N. Innocent, S. Dhanda and M. Graham, Cellular protection from oxidative DNA damage by over-expression of the novel globin cytoglobin in vitro, Mutagenesis 23 (2008), pp. 293-298.

[140] N. Shivapurkar, V. Stastny, N. Okumura, L. Girard, Y. Xie, C. Prinsen, F. Thunnissen, I. Wistuba, B. Czerniak, E. Frenkel, J. Roth, T. Liloglou, G. Xinarianos, J. Field, J. Minna and A. Gazdar, Cytoglobin, the newest member of the globin family, functions as a tumor suppressor gene, Cancer Res. 68 (2008), pp. 7448-7456.

[141] T. Burmester and T. Hankeln, A globin gene of Drosophila melanogaster, Mol. Biol. Evol. 16 (1999), pp. 1809-1811.

[142] E. Gleixner, D. Abriss, B. Adryan, M. Kraemer, F. Gerlach, R. Schuh, T. Burmester and T. Hankeln, Oxygen-induced changes in hemoglobin expression in Drosophila, FEBS J. 275 (2008), pp. 5108-5116.

[143] R. Weber and S. Vinogradov, Nonvertebrate hemoglobins: functions and molecular adaptations, Physiol. Rev. 81 (2001), pp. 569-628.

[144] D. Kraus and J. Colacino, Extended oxygen delivery from the nerve hemoglobin of Tellina alternata (Bivalvia), Science 232 (1986), pp. 90-92.

[145] D. Choi, C. Zea, Y. Do, J. Semrau, W. Antholine, M. Hargrove, N. Pohl, E. Boyd, G. Geesey, S. Hartsel, P. Shafe, M. McEllistrem, C. Kisting, D. Campbell, V. Rao, A. de la Mora and A. Dispirito, Spectral, kinetic, and thermodynamic properties of $\mathrm{Cu}(\mathrm{I})$ and $\mathrm{Cu}(\mathrm{II})$ binding by methanobactin from Methylosinus trichosporium OB3b, Biochemistry 45 (2006), pp. 1442-1453.

[146] V. Robinson, B. Smith and A. Arnone, A pH-dependent aquomet-to-hemichrome transition in crystalline horse methemoglobin, Biochemistry 42 (2003), pp. 10113-10125

[147] A. Sowa, S. Duff, P. Guy and R. Hill, Altering hemoglobin levels changes energy status in maize cells under hypoxia, Proc. Natl. Acad. Sci. U. S. A. 95 (1998), pp. 10317-10321.

[148] X. Nie and R. Hill, Mitochondrial respiration and hemoglobin gene expression in barley aleurone tissue, Plant Physiol. 114 (1997), pp. 835-840.

[149] C. Dordas, B. Hasinoff, A. Igamberdiev, N. Manac'h, J. Rivoal and R. Hill, Expression of a stress-induced hemoglobin affects NO levels produced by alfalfa root cultures under hypoxic stress, Plant J. 35 (2003), pp. 763-770.

[150] A. Igamberdiev, C. Seregélyes, N. Manac'h and R. Hill, NADH-dependent metabolism of nitric oxide in alfalfa root cultures expressing barley hemoglobin, Planta 219 (2004), pp. 95-102.

[151] S. Bruno, S. Faggiano, F. Spyrakis, A. Mozzarelli, E. Cacciatori, P. Dominici, E. Grandi, S. Abbruzzetti and C. Viappiani, Different roles of protein dynamics and ligand migration in non-symbiotic hemoglobins AHb1 and $\mathrm{AHb} 2$ from Arabidopsis thaliana, Gene 398 (2007), pp. 224-233.

[152] M. Vieweg, N. Hohnjec and H. Küster, Two genes encoding different truncated hemoglobins are regulated during root nodule and arbuscular mycorrhiza symbioses of Medicago truncatula, Planta 220 (2005), pp. 757-766.

[153] R. Sturms, S. Kakar, J. Trent and M. Hargrove, Trema and Parasponia hemoglobins reveal convergent evolution of oxygen transport in plants, Biochemistry 49 (2010), pp. 4085-4093

[154] J. Olson, A. Mathews, R. Rohlfs, B. Springer, K. Egeberg, S. Sligar, J. Tame, J. Renaud and K. Nagai, The role of the distal histidine in myoglobin and haemoglobin, Nature 336 (1988), pp. 265-266.

[155] L. Kiger, J. Uzan, S. Dewilde, T. Burmester, T. Hankeln, L. Moens, D. Hamdane, V. Baudin-Creuza and M. Marden, Neuroglobin ligand binding kinetics, IUBMB Life 56 (2004), pp. 709-719.

[156] C. Hundahl, A. Fago, S. Dewilde, L. Moens, T. Hankeln, T. Burmester and $\mathrm{R}$. Weber, Oxygen binding properties of non-mammalian nerve globins, FEBS J. 273 (2006), pp. 1323-1329.

[157] Watts R., Characterization of Nonsymbiotic Hemoglobins from Dicotyledonous Plants., Division of Biochemistry and Molecular Biology, vol. Ph.D., Australian National University, 1999. 